\title{
Beneficial Effect of Electron-Withdrawing Groups on the Sensitizing Action of Squaraines for $p$-Type Dye-Sensitized Solar Cells
}

\author{
Matteo Bonomo, ${ }^{\dagger}$ Nadia Barbero, ${ }^{\ddagger}, \|$ Fabio Matteocci, ${ }^{\S}$ Aldo Di Carlo, ${ }^{\S}$ Claudia Barolo, ${ }^{*}, \ldots$ \\ and Danilo Dini* ${ }^{\dagger}$ \\ ${ }^{\dagger}$ Department of Chemistry, University of Rome "La Sapienza”, p. le Aldo Moro 5, 00139 Rome, Italy \\ ${ }^{\ddagger}$ Department of Chemistry and NIS Interdepartmental Centre, University of Turin, via Pietro Giuria 7, 10125 Torino, Italy \\ ${ }^{\S}$ C.H.O.S.E.-Center for Hybrid and Organic Solar Energy, Department of Electrical Engineering, University of Rome "Tor Vergata”, \\ via del Politecnico 1, 00133 Rome, Italy \\ "NIS INSTM Reference Center, University of Turin, via Gioacchino Quarello 15/A, 10135 Torino, Italy
}

Supporting Information

ABSTRACT: The three squaraines (SQs) here indicated as VG1-C8, VG10-C8, and VG11-C8 (Figure 1) have been synthesized and employed as dye sensitizers of $p$-type dye-sensitized solar cells ( $p$-DSCs) when screen-printed $\mathrm{NiO}$ is the nanoporous photocathode. The photoelectrochemical performance of the three differently sensitized $p$-DSCs is compared in terms of the structural diversities among the three SQs. The $p$ DSC with VG11-C8 as sensitizer, i.e., the sole SQ with a dicyano-vinyl substituent on the central squaric ring, results in the most efficient device because of the highest values of overall conversion efficiency $(\eta>0.04 \%$ for VG11 vs $\eta<0.02 \%$ for VG1 and VG10). Moreover, VG11 is the sole SQ of the C8 series which exerts a favorable synergistic effect on the external quantum efficiency (EQE) of screen-printed NiO. The antiaggregating agent CDCA (= chenodeoxycholic acid) in the sensitizing solution of $\mathrm{NiO}$ is beneficial on the performance of the corresponding $p$-DSCs when the ratio [CDCA]/[dye] is 1:10 for all three SQs. Electrochemical impedance spectroscopy (EIS) of the SQs-sensitized $p$ -

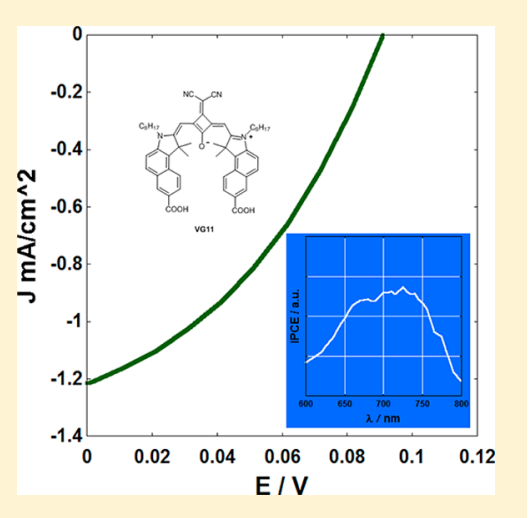
DSCs under illumination reveals that the best performing photoelectrochemical cell, i.e., the one with VG11 sensitizer, is characterized by relatively lower resistances of charge transport $(\sim 30 \Omega)$ and interfacial recombination $(\sim 90 \Omega)$, shorter hole diffusion times $(\sim 2 \mathrm{~ms})$, and a larger hole diffusion coefficient $\left(\sim 2 \times 10^{-7} \mathrm{~cm}^{2} \mathrm{~s}^{-1}\right)$ with respect to the $p$-DSCs with VG1 and VG10 dyes.

\section{INTRODUCTION}

As an alternative to the photovoltaic technologies based on $p n$ junctions the photoelectrochemical dye-sensitized solar cells (DSCs), or Grätzel cells, ${ }^{1-3}$ have received greater attention. These can be divided into $n$ - and $p$-type DSCs when oxidation and reduction are, respectively, the photoactivated electrochemical processes. $^{4-13}$ The $n$-DSCs are comparatively better than the $p$-type counterparts because $n$-DSCs are capable of reaching efficiencies of about $14 \%,{ }^{14}$ whereas $p$-DSCs ${ }^{15-19}$ display values still below $2 \%^{20-23}$ at their best $[\eta=1.67 \%$ when $\mathrm{NiO}$ is the photocathode, PMI-6T-TPA the dye sensitizer, and $\mathrm{Co}(\mathrm{II}) / \mathrm{Co}$ (III) the redox couple]. ${ }^{24,25}$ Current research efforts on $p$-DSCs are dedicated to the preparation of photocatodes with large surface area, thus affording high dye loading and large current flows via the exploration of new and improved deposition methods of the photoelectrode ${ }^{26-30}$ (typically $\mathrm{NiO}) .{ }^{15-19}$ Another important line of research is directed toward the development of dye sensitizers oppositely designed for DSC photocathodes with the aim of ameliorating the performances of the corresponding $p$-DSCs. When designing dye sensitizers for $p$-DSCs ${ }^{31}$ and eventually tandem DSCs $(t-$ DSCs $)^{32}$ with anodes and cathodes both photoelectrochemi- cally active, the following key requirements have to be fulfilled: (i) broad absorption spectrum comprising visible and NIR with high extinction coefficient; (ii) highest occupied molecular orbital (HOMO) energy of the sensitizer lying below the valence band $(\mathrm{VB})$ upper edge of the $p$-type semiconductor; (iii) lowest unoccupied molecular orbital (LUMO) energy of the sensitizer placed above the redox potential of the electrolyte to ensure efficient hole injection into the semiconductor VB and regeneration from the redox species; (iv) anchoring groups to link strongly the dye on the oxide surface and allow electronic coupling between the Fermi level of the semiconductor and the HOMO of the dye; (v) electron-withdrawing groups located far away from the semiconductor surface in order to minimize recombination phenomena and accelerate electron transfer (et) from the excited dye to the redox shuttle. In particular, it has been the last issue which has motivated the synthesis of the squaraine-denominated VG11 (Figure 1, vide infra) here proposed for the first time for $p$ -

Received: April 20, 2016

Revised: July 6, 2016

Published: July 6, 2016 

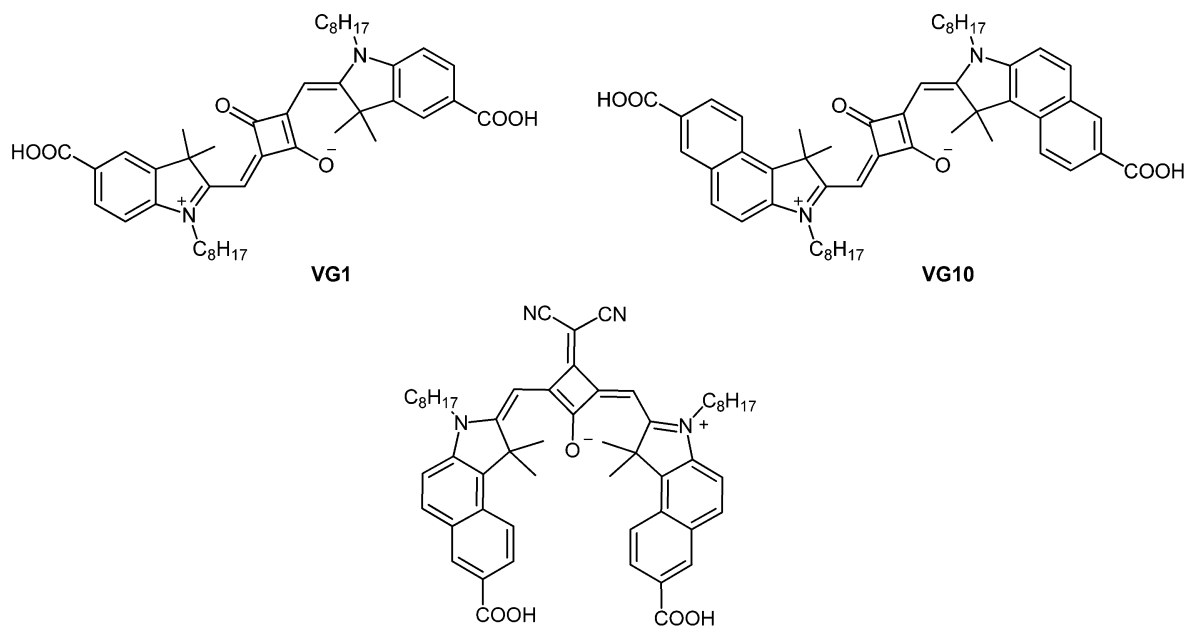

VG11

Figure 1. Structures of the three SQs VG1, VG10, and VG11 (C8 series) employed as sensitizers of $p$-DSCs with screen-printed NiO photocathodes.

DSCs. $^{33-37}$ In fact, organic dyes like $\mathrm{SQs}^{33-37}$ can be particularly suitable for photocathodes sensitization of $p$ - and mostly $t$-DSCs since in the latter device the red-shifted absorption of the SQs would complement the spectrum of the traditional organometallic ${ }^{38}$ and organic dyes ${ }^{39}$ for $n$-DSCs. Among NIR-absorbing dyes, ${ }^{34-37,40,41}$ SQs are particularly important due to the high absorption coefficient in the NIR (>550 nm, Figure ESI1) and the tunability of the structure and electronic properties. Some successful employment of SQs in $n$ DSC has been reported in the recent past, ${ }^{42,43}$ but few examples of SQs have been actually designed on purpose for $\mathrm{NiO}$-based $p$-DSCs. ${ }^{28,44,45}$ In the present contribution we synthesized the three symmetrical squaraines VG1-C8, VG10C8, and VG11-C8 (Figure 1) for their employment as dye sensitizers of screen-printed $\mathrm{NiO}$ photocathodes for $p$-DSCs.

Due to their symmetric structure the three SQs of the C8 series present easiness of preparation and simpler and cheaper procedures of purification in comparison to their unsymmetrical analogues. ${ }^{46}$ In particular, VG1 and VG10 were previously employed by us in $p$-DSCs when $\mathrm{NiO}$ cathode was prepared via screen printing with $\mathrm{CH}_{3} \mathrm{CO}_{2} \mathrm{H}$ as antiaggregating agent, $^{28}$ whereas VG11 is reported here for the first time as sensitizer of a $p$-DSCs. The three SQs differ for the extent of electronic conjugation and the electronic character, i.e., if electron withdrawing or releasing, of the substituents on the central squaric ring. VG1, VG10, and VG11 possess alkyl chains of the same length (C8) to exclude a priori differences of sensitizing action, which are ascribable to these nonelectroactive groups. Therefore, the main purpose of the present paper is to provide new directions in terms of SQ structural design for improving the still weak performances of the NiO-based $p$-DSC with SQ sensitizers. ${ }^{28,33}$ SQs generally suffer from intermolecular aggregation in the surface-anchored state $e^{47}$ due to their large size and the presence of the flat squaric central unit. Such phenomena are generally undesired in DSCs since they lower the rate of dye photoexcitation with consequent inhibition of photocharge injection. To prevent these we considered the use of the coadsorbent CDCA (chenodeoxycholic acid) during the preparation of the sensitizing solutions with VG1, VG10, and VG11. ${ }^{47-49}$ Erythrosine B (ERY) $)^{32,50-52}$ has been also utilized as benchmark sensitizer for comparative purposes. Analysis of the kinetics of the electron transfer processes in these photoelectrochemical devices differing in the nature of the SQ sensitizer will be given employing EIS. ${ }^{30,53-60}$

\section{EXPERIMENTAL SECTION}

2.1. Screen-Printing Paste Preparation. The preparation of the paste, i.e., the precursor utilized successively in the process of screen-printing deposition of $\mathrm{NiO}$, has been realized through the procedure described schematically in Table ESI1. This procedure is a slightly modified version of the one reported by Ito et al. ${ }^{61}$ for the preparation of the paste to be employed in the screen-printing deposition of $\mathrm{TiO}_{2}$ for $n$ DSCs. All chemicals were purchased from Sigma-Aldrich or Fluka at the highest degree of purity available and were used without any further purification. Anhydrous terpineol was used as a mixture of enantiomers. Grinding was realized at room conditions in a mortar with a $15 \mathrm{~cm}$ of diameter. The stirring process was carried out with a $4 \mathrm{~cm}$ long magnetic stirrer at a rotation speed of $250 \mathrm{rpm}$. Ultrasonic homogenization was performed with a Ti horn-equipped sonicator (Vibracell 72408 from Bioblock scientific). The paste we obtained had the appearance of a viscous slurry with a shelf life of about 1 year. The originality of the procedure of paste preparation reported in Table ESI1 resides on the utilization of preformed $\mathrm{NiO}$ microspheres $(\max \text { diameter }=50 \mathrm{~nm})^{28}$ instead of $\mathrm{NiO}$ chemical precursors such as $\mathrm{NiCl}_{2}$ or $\mathrm{Ni}(\mathrm{OH})_{2},{ }^{62}$ the use of which renders generally more elaborated the procedures of purification and requires more drastic conditions of sintering.

2.2. Screen-Printing Deposition of NiO Thin Films. The paste precursor was spread over a FTO-covered glass panel (item no. TCO227 from Solaronix), which has been previously cleaned in an ultrasonic bath with acetone for $10 \mathrm{~min}$ and with ethanol for $10 \mathrm{~min}$. The paste was spread via screen printing through a $90.48 \mathrm{~T}$ mesh screen on dried FTO/glass panels. After a predrying period of $15 \mathrm{~min}$ at $100{ }^{\circ} \mathrm{C}$ in an oven (WHT $5 / 120$ from Welland), the temperature of the oven was increased with a temperature ramp of $15^{\circ} \mathrm{C} / \mathrm{min}$ until $450{ }^{\circ} \mathrm{C}$. The screen-printed slurry of $\mathrm{NiO}$ nanoparticles was kept at the highest temperature for $30 \mathrm{~min}$ to complete sintering. After sintering the resulting mesoporous film of $\mathrm{NiO}$ was cooled down to ambient temperature with the attainment of a $2 \mu \mathrm{m}$ thick film of $\mathrm{NiO}$. The thickness $(l)$ of the $\mathrm{NiO}$ film was estimated with a Dektat 150R profilometer from Veeco. The imaging of the surface morphology of mesoporous $\mathrm{NiO}$ film 
(Figure 2) was realized with a scanning electron microscope (SEM, Auriga Zeiss 170 instrument). The advantage of such a

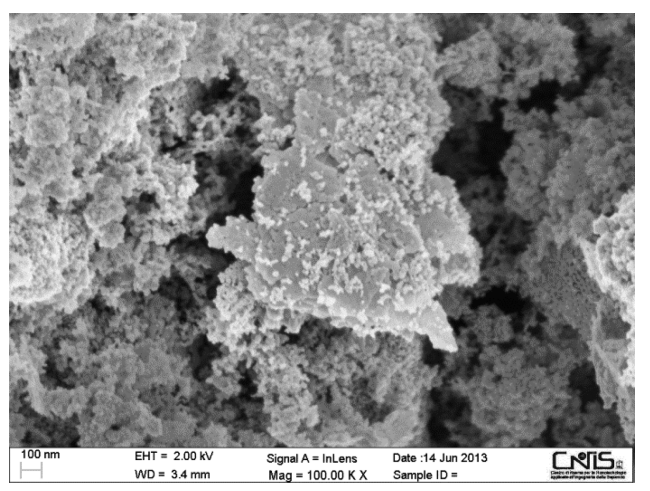

Figure 2. SEM picture of the surface morphology of mesoporous $\mathrm{NiO}$ thin film $(l=2 \mu \mathrm{m})$ deposited via screen-printing.

procedure is the lower temperature of processing $(\leq 400-450$ ${ }^{\circ} \mathrm{C}$ ) with respect to sol-gel method $\left(>400-500{ }^{\circ} \mathrm{C}\right) .{ }^{63,64}$ The presence of preformed nanoparticulated $\mathrm{NiO}$ in the starting paste forces the heat to sinter solely the metal oxide nanoparticles ${ }^{65}$ with no need of activating chemical reactions for metal oxide formation. At the adopted temperature of sintering the cellulose-based binders of the paste are completely combusted and removed as a volatile product of thermolysis from the oxide layer. The resulting oxide in the pristine state generally presents nonstoichiometric features for the copresence of nickel sites with valence II and III. ${ }^{65,66}$ For this reason it would be more appropriate to report it with the formula $\mathrm{NiO}_{x}$.

2.3. Synthesis of Squaraines. The details of the synthesis of VG1-C8, VG10-C8, and VG11-C8 have been previously reported by our groups in the studies presented in refs 33 and 67.

2.4. p-DSC Assembly and Testing. Screen-printed $\mathrm{NiO}$ photocathode and the platinized FTO counter electrode were assembled together in a sandwich configuration using as a Bynel thermoplastic polymeric film having the dual function of spacer and sealant. Platinized counter electrodes were prepared by screen printing platinum paste $\mathrm{Ch01}$ from Chimet through a $100 \mathrm{~T}$ mesh screen onto FTO-coated glass. ${ }^{68}$ Sensitization of screen-printed $\mathrm{NiO}$ photocathodes was realized by dipping the $\mathrm{NiO}$ films in a $0.2 \mathrm{mM}$ dye sensitizer solution (either with or without CDCA) using ethanol as solvent. All screen-printed $\mathrm{NiO}$ samples were sensitized at room temperature for $2 \mathrm{~h}$. After sandwiching the electrodes, the triiodide/iodide-based electrolyte [commercial Iodolyte Z-150 from Solaronix, Aubonne $(\mathrm{CH})$ ] was injected inside the cell by means of the vacuum backfilling technique. The hole for electrolyte injection was sealed with a liquid resin [TB3035B from ThreeBond, Tokyo (JP)], which becomes a hard paste upon UV curing treatment. The photoactive area of the samples was $0.25 \mathrm{~cm}^{2}$.

Optical transmittance was measured with a double-ray spectrometer [UV-2550 by Shimazdu, Kyoto (JP)]. Photoelectrochemical performances consisting in the determination of the characteristic curves current-potential (JV) were evaluated using the solar simulator Solar Test $1200 \mathrm{KHS}$ (class B) at $1000 \mathrm{~W} \mathrm{~m}^{-2}$ with artificial solar spectrum AM 1.5 G. The curves of IPCE (= incident photon to current conversion efficiency, see ESI for fundamental photoelectrical equations) ${ }^{69}$ were recorded using a computer-controlled setup consisting of a Xe lamp (model 70612, Newport) coupled to a monochromator (Cornerstone 130 from Newport) and a Keithley 2002420 light-source meter.

The EIS measurements were performed with an AUTOLAB PGSTAT12 from Metrohm at the condition of open-circuit potential in dark conditions and under solar simulator illumination. ${ }^{70}$ For the sole EIS experiments conducted under illumination the applied potential was modulated within \pm 20 $\mathrm{mV}$ with respect to the value of the open-circuit potential. This was made in order to evaluate the variations of all key parameters characterizing the equivalent circuit fitting the electrochemical impedance spectra (vide infra). In the EIS experiments the potential perturbation had an amplitude of $10^{-2} \mathrm{~V}$. The frequency range of the impedance perturbation varied depending on the state of the cell, i.e., if illuminated or not. Impedance spectra were recorded within the frequency ranges $10^{-1}-10^{5}$ and $10^{-2}-10^{5} \mathrm{~Hz}$ when the cell was under illumination and in dark conditions, respectively. Electrochemical impedance spectra were fitted using Z-View software from Scribner Associates Inc. In the context of impedance spectra simulation of NiO-based $p$-DSCs we developed a new equivalent circuit adapting the transmission line model first proposed by Bisquert et al. for the impedance analysis of $\mathrm{TiO}_{2}$ based $n$-DSCs with gel electrolytes.

\section{RESULTS AND DISCUSSION}

3.1. Optical Characterization of Sensitized NiO. The absorption spectra of VG1, VG10, and VG11 in ethanol at room temperature (see Figure ESI1) indicate 643, 671, and 710 $\mathrm{nm}$ as values of $\lambda_{\mathrm{MAX}}$ for VG1, VG10, and VG11, respectively, with $\varepsilon\left(\lambda_{\mathrm{MAX}}\right)$ progressively decreasing upon increase of $\lambda_{\mathrm{MAX}}$ in the triad of chosen dyes. The red shift observed in passing from VG1 to VG10/VG11 is related to the larger extent of electronic conjugation in passing from the indoleninic unit of VG1 to the benzoindoleninic unit of VG10/VG11 (Figure 1), whereas the further red shift observed on going from VG10 to VG11 is ascribed to the presence of the dicyano-vinyl chromophoric unit. $^{33,67}$ The resulting effect of sensitization of the $\mathrm{NiO}$ cathode (Figure 3) reflects the optical absorption differences already observed in the solution spectra of VG1, VG10, and VG11 (see Figure ESI1).

The efficacious sensitization of screen-printed $\mathrm{NiO}$ is a consequence of its open and scale-like morphology (Figure 2),

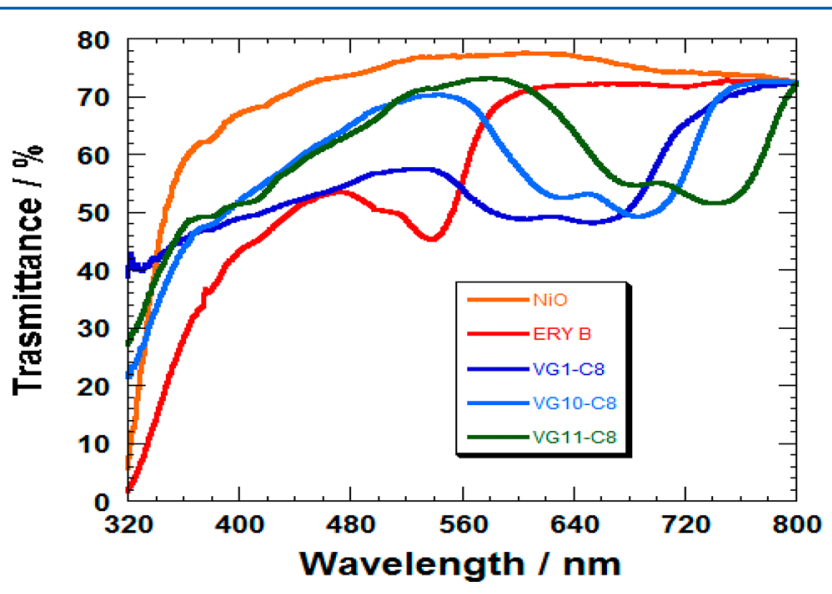

Figure 3. Transmittance variation of screen-printed $\mathrm{NiO}$ in passing from the pristine to the sensitized state with the C8 series of the three SQs under consideration (Figure 1) and with ERY as comparative dye. 
which is characterized by cavities and apertures having a linear size on the order of a few hundred nanometers. Such voids warrant the wettability of $\mathrm{NiO}$ by the solution of sensitization as well as liquid electrolytes throughout the whole thickness of the oxide film. As the main consequence, this morphological feature brings about the observation of the direct proportionality between layer thickness and the extent of electrical current exchanged by the $\mathrm{NiO}$ electrode when the latter constitutes the actual electroactive species. ${ }^{60,72,73}$ When CDCA (Figure ESI2) is added to the solution of sensitization, the corresponding variations of $\mathrm{NiO}$ optical transmittance (Table ESI2) are directly correlated to the relative concentration of the dye sensitizer with respect to CDCA (Figure 4). Upon increasing antiaggregating agent concentration in the sensitizing solution, the amount of chemisorbed CDCA correspondingly increases with consequent diminution of the quantity of chemisorbed dye as evinced by the increase of transmittance ion correspondence of the characteristic absorption peaks of the colorants (Figure 4 and Table ESI2). It is here anticipated that for these SQs a higher dye loading is not necessarily associated with an improvement of the photoelectrochemical performance in the corresponding $p$-DSC, as previously observed with analogous systems, ${ }^{42}$ and an optimum concentration ratio does exist (vide infra). At the maximum concentration of CDCA (200 mM) employed by us in the sensitization solution, the transmittance spectrum of VG1- and VG10-sensitized oxide does not indicate any optical evidence of the presence of anchored sensitizer (Figure 4, top and middle frames). This is not the case of VG11-sensitized $\mathrm{NiO}$, the spectrum of which shows the typical absorption features of VG11 [Figures 3 and 4 (bottom frame)]. A possible reason at the basis of such observed differences could be due to a different geometry of anchoring for the diverse SQs for which calculations in the gas phase have predicted that VG11 possesses a trans form with respect to the bonds linking the squaraine core to the benzoindoleninic moieties (Figure 1) as most stable configuration, while VG1 and VG10 have the cis form with respect to the same type of bonds as the most favorable configuration. ${ }^{67,74}$ As a consequence of these theoretical considerations we expect that the geometry of chemisorption for the three SQs under investigation follows the two main schemes presented in Figure 5. According to this depiction the geometry of anchoring of one molecular unit of trans VG11 does not impede the occupancy of the vicinal sites of anchoring to a second molecule of trans VG11.

This would keep a relatively higher surface concentration of the anchoring sites actually accessible to the other molecules of trans VG11 (perpendicularly oriented with respect to $\mathrm{NiO}$ surface) in comparison to the situation with cis VG1 and cis VG10. In fact, upon chemisorption the two latter systems are expected to prevent further occupancy of the vicinal sites of anchoring because of their hypothetical parallel orientation with respect to the $\mathrm{NiO}$ surface as sketched in Figure 5. It is also expected that the process of trans VG11 chemisorption is favored kinetically with respect to the chemisorption of cis VG1 and VG10 (Figure 5). This is because the rate of dye chemisorption (a heterogeneous process of second order) ${ }^{75}$ is directly proportional to the product $[\mathrm{SQ}]\left[\square_{\mathrm{NiO}}\right]_{\text {surf }}$, where $\left[\square{ }_{\mathrm{NiO}}\right]_{\text {surf }}$ represents the surface concentration of the $\mathrm{NiO}$ anchoring sites available to the dye. The parameter $\left[\square_{\mathrm{NiO}}\right]_{\text {surf }}$ varies with the nature of the SQ and its geometry of chemisorption and is supposed to be larger for trans VG11with respect to cis VG1 and VG10 by virtue of the given
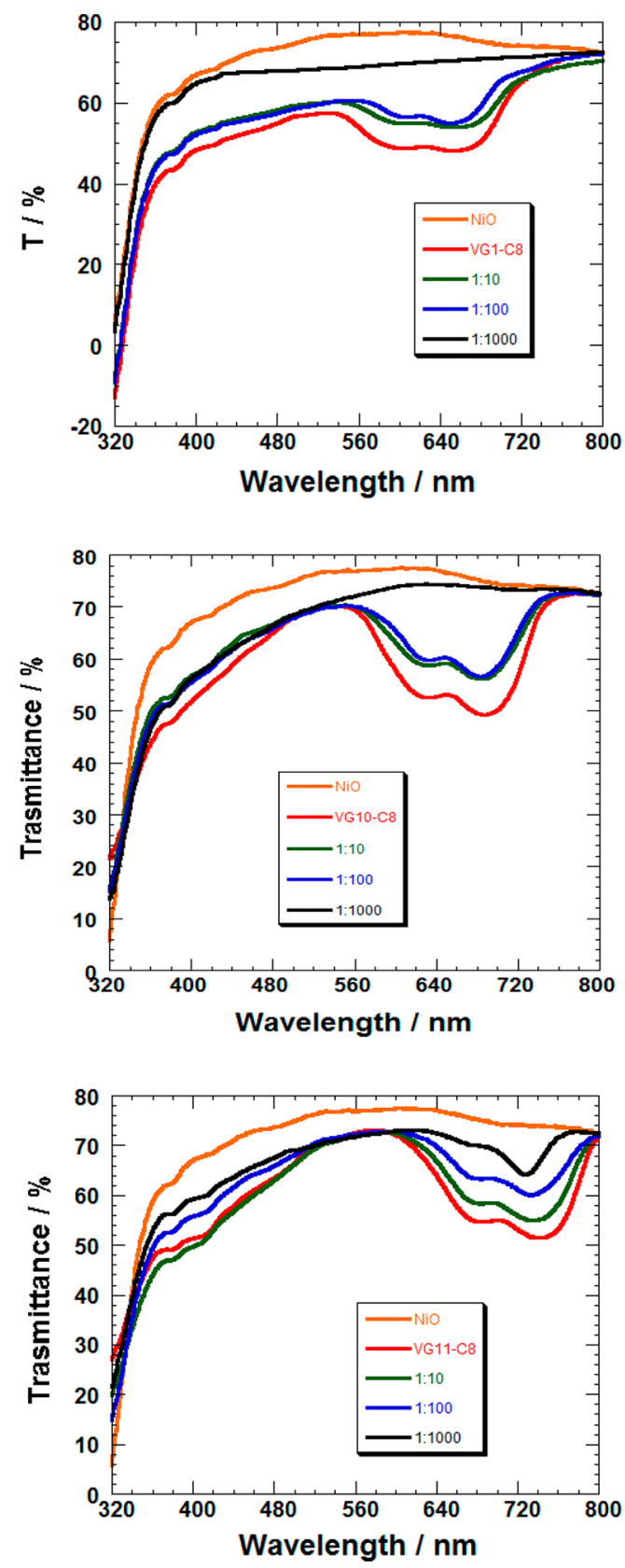

Figure 4. Transmittance spectra of SQ-sensitized $\mathrm{NiO}$ films when different concentrations of CDCA were used in the sensitizing solution. Dyes: VG1 (top), VG10 (middle), and VG11 (bottom). Red trace refers to the spectrum of $\mathrm{NiO}$ sensitized in CDCA-free solution. Orange profile refers to the spectrum of pristine $\mathrm{NiO}$. Ratios in the insets indicate the concentration ratio $[\mathrm{dye}] /[\mathrm{CDCA}]$ in the solution of sensitization.

hypothetical geometry of dye anchoring (Figure 5). Under the conditions of sensitization with molar ratio SQ/CDCA $=1$ / 1000 , the SQs with slower kinetics of chemisorption, i.e., VG1 and VG10 (vide supra), apparently are not fast enough to be chemisorbed by the $\mathrm{NiO}$ surface because of the relatively very large concentration of CDCA which occupies in a shorter time all the anchoring sites available on the $\mathrm{NiO}$ surface. This hypothesis would explain the lack of any evidence of SQ optical signature in the spectrum of $\mathrm{NiO}$ electrode sensitized at the condition $[\mathrm{SQ}] /[\mathrm{CDCA}]=1 / 1000$ with $\mathrm{SQ}=\mathrm{VG} 1$ and VG10 (Figure 4, top and middle plots). In contrast, VG11 would 


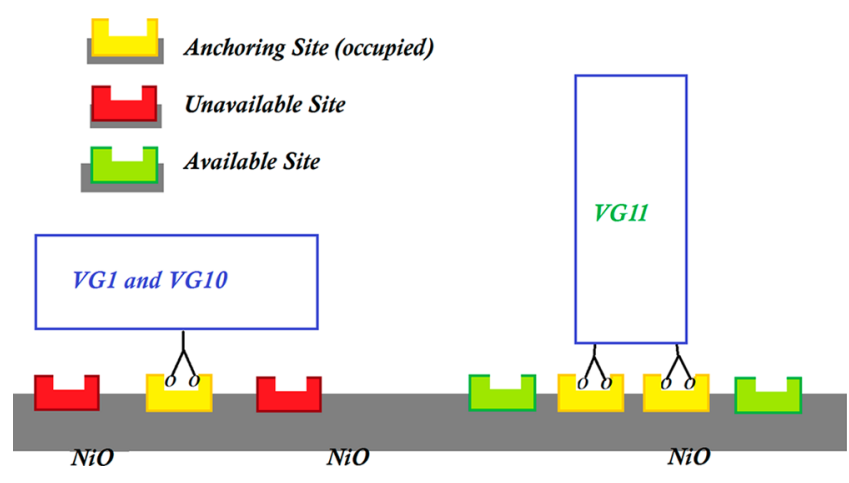

Figure 5. Expected geometry of SQs chemisorption on $\mathrm{NiO}$ for the most stable configurations of VG1, VG10, and VG11. Differently colored boxes indicate the sites of anchoring on $\mathrm{NiO}$ surface. For sake of simplicity we omitted the second carboxylic unit of VG1 and VG10 systems, which is employed for molecular anchoring.

manage to get anchored on the $\mathrm{NiO}$ surface also from the solution more highly concentrated in CDCA prior to saturation of $\mathrm{NiO}$ surface sites by CDCA because of the faster kinetics of VG11 chemisorption with respect to the analogous processes of VG1 and VG10. At the moment we do not have clear experimental evidence of the actual molecular orientation of this series of SQs on the NiO surfaces for $p$-DSCs. This type of study can be conducted with XPS and/or ATR-FTIR techniques, ${ }^{66,76-80}$ which, in turn, require a flat surface morphology as well as exposed single-crystal faces. As previously evidenced, the sensitized $\mathrm{NiO}$ samples here investigated are polycrystalline ${ }^{65}$ and present mesoporous morphology (Figure 1) with no preferred surface orientation. These structural and morphological features somewhat limit the meaningfulness of such surface studies that should be apt to provide an indication of the molecular orientation for these complex sensitized systems. The anchoring of CDCA on mesoporous $\mathrm{NiO}$ cannot be considered innocent in optical terms: $\mathrm{NiO}$ films immersed in highly concentrated solutions of CDCA and in the absence of dye sensitizer presented a spectrum with lower optical transmission than pristine $\mathrm{NiO}$ within the window 330-650 nm (not shown). Moreover, the observed shifts of transmission minima for the SQ-sensitized spectra obtained from the sensitization solutions with the largest concentrations of CDCA (see Table ESI2) could be the consequence of dye protonation (halochromic effect of SQ dyes). ${ }^{81}$

3.2. Photoelectrochemical Characterization of SQ-Sensitized $p$-DSCs. The characteristic JV curves of the $p$-DSCs differing for the conditions of $\mathrm{NiO}$ photocathode sensitization are presented in Figure ESI3. The corresponding parameters of short-circuit current density $\left(J_{\mathrm{SC}}\right)$, open-circuit potential $\left(V_{\mathrm{OC}}\right)$, fill factor $(\mathrm{FF})$, and overall efficiency $(\eta)$ are reported in Table 1. The conditions of $\mathrm{NiO}$ electrode sensitization with ERY colorant have been previously reported in refs 51 and 52 .

From the $J V$ data summarized in Table 1 it results that the $p$ DSCs with the largest overall efficiencies were those sensitized with VG11 $(\eta=0.043 \%)$ and the dye-benchmark ERY $(\eta=$ $0.032 \%)$. VG1 and VG10 as photocathode sensitizers inhibited the intrinsic photoeletrochemical activity of screen-printed $\mathrm{NiO}$ in the bare state as evinced from the decrease of the overall efficiencies $(0.020 \%$ for bare $\mathrm{NiO}$ vs $0.018 \%$ of VG1- and VG10-sensitized NiO, Table 1). This trend could be ascribed to a photoinjection not sufficiently sustained by excited VG1 and VG10 with respect to pristine $\mathrm{NiO}$. Dye anchoring thus
Table 1. Comparison of the Main Photovoltaic Parameters Obtained from the $J V$ Curves of the $p$-DSCs with Bare NiO Photocathode and Differently Sensitized NiO Electrodes (see Figure ESI3) $^{a}$

$\begin{array}{lrcccc}\text { dye } & \text { CDCA:SQ } & V_{\mathrm{OC}}(\mathrm{mV}) & J_{\mathrm{SC}}\left(\mathrm{mA} / \mathrm{cm}^{2}\right) & \mathrm{FF}(\%) & \eta(\%) \\ \text { VG1-C8 } & 0: 1 & 83 & -0.433 & 37.99 & 0.014 \\ & 10: 1 & 87 & -0.577 & 37.20 & 0.018 \\ & 100: 1 & 77 & -0.499 & 37.40 & 0.014 \\ & 1000: 1 & 80 & -0.258 & 30.99 & 0.006 \\ \text { VG10-C8 } & 0: 1 & 99 & -0.363 & 40.38 & 0.015 \\ & 10: 1 & 102 & -0.435 & 40.87 & 0.018 \\ & 100: 1 & 100 & -0.427 & 39.78 & 0.017 \\ & 1000: 1 & 98 & -0.140 & 41.47 & 0.005 \\ \text { VG11-C8 } & 0: 1 & 95 & -0.994 & 35.70 & 0.035 \\ & 10: 1 & 93 & -1.160 & 36.12 & 0.043 \\ & 100: 1 & 94 & -0.885 & 35.47 & 0.030 \\ & 1000: 1 & 88 & -0.576 & 35.56 & 0.018 \\ \text { ERY B } & & 88 & -1.019 & 36.02 & 0.032 \\ \text { bare NiO } & & 96 & -0.521 & 40.76 & 0.020\end{array}$

${ }^{a}$ The effect of CDCA concentration in the sensitization solution on the corresponding $p$-DSC performance with SQ dyes is shown for four predefined values of the molar ratio CDCA:SQ in the solution of sensitization. ERY is used as benchmark sensitizer for comparative purposes.

produces a counterproductive effect. The sole colorant that does not exert an inhibiting effect on the photoelectrochemical activity of bare $\mathrm{NiO}$ resulted in the systen VG11. To our knowledge this is the first case of a SQ sensitizer which does not produce the inhibition of substrate photoactivity when a NiO-based $p$-DSC is analyzed. ${ }^{28,70,82}$ When the overall efficiency of the series of VG-sensitized p-DSCs is analyzed, the best performing set of cells was the one that adopted the concentration ratio $[\mathrm{CDCA}]:[\mathrm{SQ}]=10: 1$ in the solution of sensitization no matter the nature of the dye (Table 1 ). The existence of an optimal CDCA/SQ ratio for the effective inhibition of deleterious intermolecular interactions between the molecules of anchored dye could be a consequence of the existence of an allotted number of surface sites for the chemisorption of non- (or poorly) interacting dye sensitizers. This surface-dependent effect would explain why larger values of the $[\mathrm{CDCA}]:[\mathrm{SQ}]$ ratio would drastically decrease the amount of anchored dye whereas the total lack of disaggregating agent in the sensitizing solution would not impede at all the creation of dye aggregates on the electrode surface. The existence of such aggregates is recognized as responsible for the photophysical behavior that would follow altered and probably less efficient mechanisms of photoexcitation, photoinjection, and dye regeneration with respect to noninteracting dye molecules in the anchored state. Another possible influence of CDCA on the photoelectrochemical behavior of SQ-based $p$-DSCs could be related to the acidic nature of the disaggregating agent that can modify the state of charge of the colorant (vide supra). The protonation of the dye generally represents a beneficial event in the context of photoelectrochemical reduction since the positive charge of the dye is expected to promote the electron transfer from the valence band of $\mathrm{NiO}$ to the protonated dye, thus realizing the process of hole injection at a presumably higher rate with respect to a nonprotonated dye. The latter statement derives from elementary electrostatic considerations. The most efficient VG-based photoelectrochemical cells presented also the highest 
values of $J_{\mathrm{SC}}$ values (Table 1 ), whereas $\mathrm{FF}$ values remained stable around $35-40 \%$ (as typically found for NiO-based $p$ DSCs $)^{20}$ and were thus poorly dependent on the amount of CDCA in the sensitizing solution (Table 1). The parameter $V_{\mathrm{OC}}$ tended to decrease as CDCA concentration increased in the sensitizing solution (Table 1). This fact indicated the direct proportionality between the open-circuit photovoltage and the amount of dye actually present on the electrode surface. It is worth to notice that the VG10-sensitized photoelectrode presented the generally largest values of $V_{\mathrm{OC}}$, i.e., a parameter that is related principally to the lifetime of the holes once photoinjected in the oxide electrode. The larger value of opencircuit potential should correspond to the larger surface concentration of photoinjected charges (and not necessarily to larger a dye sensitizer surface concentration) and the smaller rate of recombination between photoholes and the photoproduct of reduction ( $\mathrm{I}^{-}$in the present case) because of the longer hole lifetime on the $\mathrm{NiO}$ surface. The reason why VG10 produces a larger value of $V_{\mathrm{OC}}$ than VG1 is found in the larger size of the conjugated moiety present in VG10 with respect to VG1 (benzoindoleninic vs indoleninic unit). The larger benzoindoleninic unit in VG10 would then act as a more efficient spacer between the hole localized on the surface electrode and the site of recombination where iodide is present. The anion iodide is expected to be directly absorbed either on the positively charged $\mathrm{NiO}$ electrode surface or in the electrolyte side of the electrode/electrolyte interface. Therefore, the dye in this case would act as a separator between the hole and iodide as a function of its molecular extension. This, in turn, would reduce the time probability with which the hole recombines with the reduced form of the redox mediator and leads to the resulting increase of $V_{\mathrm{OC}}$. This consideration is based on the assumption that all SQs here considered anchor through both carboxylic groups present in the structure. The given explanation founded on the different molecular sizes of VG1 and VG10 sensitizer no longer holds when the trend of $V_{\mathrm{OC}}$ refers to the comparison of VG10- and VG11-based photoelectrochemical cells for the supposition we made on the geometry of molecular anchoring shown in Figure 5. At the basis of the smaller value of $V_{\mathrm{OC}}$ for the VG11-sensitized $p$ DSC (Table 1) it is believed that the presence of the strong electron-withdrawing dicyano-vinyl group plays a relevant role. In fact, an electron-attracting group tends to recall electrostatically the photoinjected positive charge in the absence of a current flow which, in turn, would displace the injected holes by diffusion toward the site of charge collection at the $\mathrm{FTO} / \mathrm{NiO}$ interface. The attraction exerted by the dicyano-vinyl group on the photoinjected positive hole will favor kinetically the process of recombination between the hole and iodide in the absence of a current flow with respect to the situation occurring with the VG10- sensitized $p$-DSC. The best performing SQ $p$-DSCs, i.e., those obtained from sensitization solutions with [CDCA]:[dye] $=10: 1$, were compared with the photoelectrochemical cell utilizing the benchmark sensitizer ERY (Figure ESI3). VG1 and VG10 showed lower efficiencies with respect to ERY mainly because of the lower $J_{\text {SC }}$ (Table 1). The sole SQ-based cell that presented larger and more efficient parameters of photoconversion with respect to the ERY-sensitized cell was the one with VG11 sensitizer. The efficiency of $0.043 \%$ reached by the VG11-sensitized $p$-DSC represents a record value for the $\mathrm{NiO}$ based $p$-DSCs with symmetrical SQ sensitizers when $\mathrm{I}_{3}^{-} / \mathrm{I}^{-}$is the redox shuttle and SQ constitutes the sole chromophoric unit. $^{28,45,70,82}$ This finding evidences the importance of molecular design in the definition of VG11 structure as purposely designed sensitizer for $\mathrm{NiO}$ based $p$-DSCs. In fact, the adoption of VG11 led to the production of $p$-DSCs with larger conversion efficiencies and superior photoelectrochemical performances with respect to the other SQs which were not specifically designed for the application of $p$-DSC.

The complete set of the IPCE spectra for the differently sensitized $p$-DSCs has been presented in Figure ESI4. From the latter a selection of the IPCE spectra produced by the bestperforming $p$-DSCs with all dye sensitizers here considered has been made. These spectral profiles are shown in Figure 6.

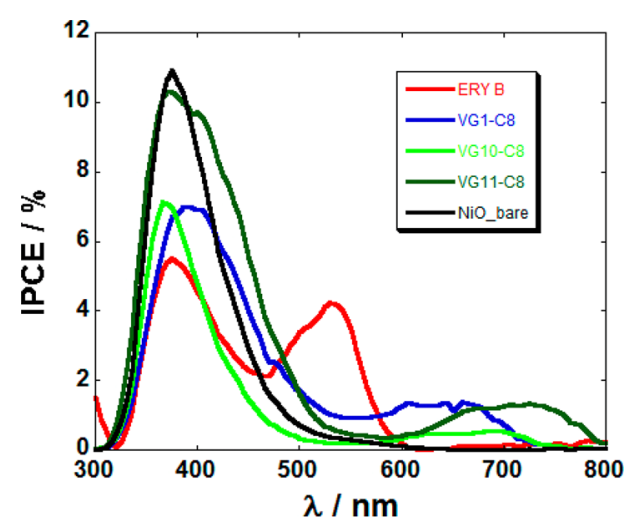

Figure 6. IPCE spectra of the NiO-based p-DSCs when the photocathode was sensitized with VG1 (blue curve), VG10 (green curve), and VG11 (dark green curve) at the optimal molar ratio $\mathrm{CDCA}: \mathrm{SQ}=10: 1$ for the sensitization solution. For comparative purposes the IPCE spectra of the $p$-DSCs utilizing the same screenprinted $\mathrm{NiO}$ photocathode in the bare (black trace) and in the ERYsensitized (red trace) states are displayed.

The curves of the photoelectrochemical spectral efficiency (Figures ESI4 and ESI6) are consistent with the observed trends of overall efficiencies and $J_{\mathrm{SC}}$ determined by the characteristic $J V$ curves (Figure ESI3 and Table 1). Moreover, the peaks of EQE corresponded to the absorption peaks obtained from the conversion of the transmittance data presented in Figure ESI1 into absorption data through the relationship $A(\lambda)=\log [1 / T(\lambda)]$ with $T \leq 1$. The use of the most efficient sensitizer, i.e., VG11, brings about two main consequences on the IPCE spectrum of the corresponding $p$ DSC: (i) induces photoelectrochemical activity in the spectral range of VG11 optical absorption, as expected for a normal completion of the function of sensitization (Figures 3 and ESI1); (ii) it does not inhibit the intrinsic photoelectrochemical activity of bare $\mathrm{NiO}$ centered at about $370 \mathrm{~nm}$ (Figure 6). Therefore, dye sensitizers VG1, VG10, and ERY actually behave as agents of photoelectrochemical passivation toward $\mathrm{NiO}$ substrate itself. When high concentrations of CDCA are employed (practically for [CDCA] $>0.01 \mathrm{M}$ ) in the solution of $\mathrm{NiO}$ pseudosensitization, i.e., no colorant is present, a dramatic decrease of the characteristic peak of bare $\mathrm{NiO}$ photoelectrochemical activity in the near UV (Figure 6) is observed in the relative IPCE spectra (Figure ESI5) and a general worsening of the photoelectrochemical performance of $\mathrm{NiO}$ is observed in the associated $J V$ curves (Figure ESI6).

In the case of $\mathrm{NiO}$ sensitization with VG10 it was clear that the intrinsic photoelectrochemical activity of $\mathrm{NiO}$ in the near UV dropped more sensibly for the photocathode treated with the sensitizing solution having the largest ratio [CDCA]: 
[VG10] (= 1000:1). This is an indication of the fact that the SQ dyes present a generally higher affinity of anchoring onto the $\mathrm{NiO}$ surface with respect to the antiaggregating agent CDCA. Besides the occupancy of the allotted sites of anchoring (Figure 5), the CDCA would play also a non-negligible role of passivating agent toward the photoelectrochemical activity of $\mathrm{NiO}$ (Figures ESI5 and ESI6).

The IPCE spectra obtained with the NiO-based $p$-DSCs here presented which utilize triiodide/iodide as redox couple (Figures ESI4 and ESI5) include contributions from the photoexcitation of different light-absorbing species that act (either in a synergistic or in an independent fashion) in quite distinct portions of the spectrum. Upon determination of the IPCE spectra of VG11-sensitized p-DSC with sensitization molar ratio $[\mathrm{CDCA}]:[\mathrm{SQ}]=100: 1$ in both the back and front modalities of illumination (see Figure ESI7) a comparison of the IPCE profiles allows distinction of the various contributions to the photocurrent of reduction due to the different species with specific light-absorbing properties: triiodide in the range $350-400 \mathrm{~nm},{ }^{83,84} \mathrm{NiO}$ in the near UV range 300-480 $\mathrm{nm},{ }^{30,51,52,70,85}$ and VG11 in the wavelength range 580-800 $\mathrm{nm}$ (Figures ESI4 and ESI7) taking into account the specific optical absorption properties of the triiodide/iodide-based electrolyte (Figure ESI8). We stress here the importance of $\mathrm{NiO}$ as the main photoelectrochemically active species in this type of photoconversion devices for the presence of superficial $\mathrm{Ni}(\mathrm{III})^{66}$ centers as defective and photoactive sites of the oxide surface. It is widely acknowledged that these defective centers in nonstoichiometric nickel oxide originate the near UV absorption displayed by bare nickel oxide ${ }^{18,19}$ (see Figure 3, orange trace) to which is associated the observed photoelectrochemical activity in the near UV, no matter the nature of the redox shuttle. ${ }^{24,30,51,52,70,85}$ With these considerations we are prone to minimize the importance of the triiodide species with respect to $\mathrm{NiO}$ as mainly responsible for the photoelectrochemical activity detected with NiO-based p-DSCs. Another finding which supports the relative importance of $\mathrm{NiO}$ vs triiodide as the main photoelectrochemically active species in the near UV is the observation of a strong dependence of the photoelectrochemical activity of $\mathrm{NiO}$ when this is treated with CDCA. It has been previously outlined how the overall conversion efficiency and the IPCE of the $p$-DSCs employing noncolored $\mathrm{NiO}$ samples that have been previously treated with CDCA decrease heavily upon increasing CDCA concentration in the sensitization solution (Figures ESI5 and ESI6). This effect of CDCA has been ascribed to the photoelectrochemical passivation of the active $\mathrm{Ni}$ (III) centers by such an antiaggregating agent. In doing so, we believe that CDCA behaves as a blinding agent for the photoactive $\mathrm{Ni}$ (III) centers on the oxide surface. If the main photoexcitation process at the basis of the origin of the observed cathodic photocurrent in NiO-based $p$-DSCs was activation of triiodide, the phenomenon of CDCA passivation of the $\mathrm{NiO}$ surface would have not produced such a strong effect of photoinhibition. Moreover, a comparison of the IPCE profiles obtained from back and front illumination (Figure 6 and Figure ESI7) would have not been characterized by the most profound differences in correspondence to $\mathrm{NiO}$ characteristic absorption (Figure 4), even in the absence of CDCA treatment. ${ }^{70}$

3.3. Electrochemical Characteristics of SQ-Sensitized $p$ DSCs. Dark JV curve measurements were conducted on the most efficient photoelectrochemical cells sensitized with SQs at a molar ratio of sensitization $[\mathrm{CDCA}]:[\mathrm{SQ}]=10: 1$ (Table 3 ) on the ERY-sensitized $p$-DSC and on the $p$-DSC with bare $\mathrm{NiO}$ cathode (Figure ESI9 and Table ESI3). The dark current of the $p$-DSCs originated from a reduction process with current values with negative sign and refer to the dark reduction of triiodide to iodide $\mathrm{I}_{3}^{-}+2 \mathrm{e}^{-} \rightarrow 3 \mathrm{I}^{-}$. This occurs at the dye-NiO/ electrolyte interface and, eventually, at the FTO/electrolyte interface. The FTO/electrolyte interface intervenes in the electrochemical process if there is no compact layer of $\mathrm{NiO}$ or any insulating layer like $\mathrm{Al}_{2} \mathrm{O}_{3}$, which would prevent the phenomenon of shunting between FTO substrate and the electrolyte. In the present work we have not considered the deposition of a compact layer of $\mathrm{NiO}$ for prevention of such a phenomenon, and it is planned to consider this type of modified $\mathrm{NiO}$ photocathode in a successive study. Under these circumstances shunting can take place at the FTO/electrolyte interface if the first layer of nanoporous $\mathrm{NiO}$ in contact with FTO does not cover uniformly the transparent conductive substrate.

Except VG11, in dark conditions all dyes led to an increase of the dark open-circuit voltage in the corresponding $p$-DSC with respect to cell with bare $\mathrm{NiO}$ cathode. This implies that part of the surface charge present in the sensitized cathode originates either from a process of dark charge transfer between the dye and the $\mathrm{NiO}$ substrate or from a process of anion adsorption the extent of which depends on the nature of the anchored sensitizer, its surface concentration, and the nature of the adsorbed anion. The analysis of the dependence of dark $J_{S C}$ on the nature of the sensitizer (Table ESI3) revealed that only the sensitization with ERY produces cells with a larger value of dark $J_{\mathrm{SC}}$ with respect to the $p$-DSC with bare $\mathrm{NiO}$ cathode (Figure ESI9). This implicates that within the C8 series here investigated none of the three SQs actually mediates the process of dark electron transfer from $\mathrm{NiO}$ to triiodide species. Among SQs only VG11 behaved as an agent of passivation for $\mathrm{NiO}$ toward the dark reduction process $\mathrm{I}_{3}^{-}+2 \mathrm{e}^{-} \rightarrow 3 \mathrm{I}^{-}$as evinced from the net decrease of the dark $J_{\mathrm{SC}}$ in passing from bare $\mathrm{NiO}$ to VG11-sensitized p-DSC (Table ESI3). This indicated that VG11 does not intervene directly as a mediator during such a cathodic process in dark conditions, i.e., in the absence of any photoexcitation, and prevents the dark electrochemical reduction of triiodide by $\mathrm{NiO}$. Therefore, triiodide reduction in dark conditions involves solely the intervention of $\mathrm{NiO}$ (and eventually the one of FTO exposed to the electrolyte). Conversely, the doubling of dark $J_{S C}$ in passing from the electrochemical cell with bare $\mathrm{NiO}$ cathode to its ERY-sensitized version evidences the participation of ERY sensitizer as surface-immobilized redox mediator during the process of dark reduction of the triiodide species. ${ }^{70}$

3.4. Electrochemical Impedance Spectra of SQ-Sensitized $p$-DSCs. The electrochemical impedance spectra of the best performing SQ-sensitized $p$-DSC and the photoelectrochemical cell utilizing ERY colorant have been recorded. These are shown in Figure 7. In the determination of the EIS profiles we have not considered the impedance analysis of the $p$-DSC with VG1-C8 sensitizer due to its poorer performance in comparison to the photoelectrochemical cells employing the other two SQs and the benchmark dye ERY.

For the analysis of the EIS data in Figure 7 we used an equivalent circuit that represents an adaptation of the one developed by Bisquert et al. for the EIS analysis of $\mathrm{TiO}_{2}$-based $n$-DSCs (Figure 8). ${ }^{86}$

The equivalent circuit here proposed consists of three main elements which are connected in series: (i) the series resistance 


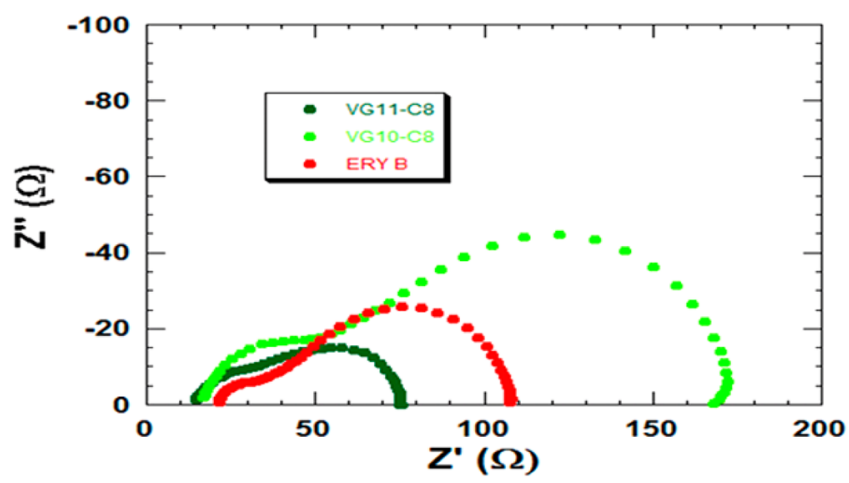

Figure 7. Nyquist plots of the electrochemical impedance spectra of the $p$-DSC sensitized with ERY (red dots) and the best performing SQs VG10 (light green dots) and VG11 (dark green dots) at the respective values of open-circuit potential. $V_{\mathrm{OC}}=90,100$, and $90 \mathrm{mV}$ for ERY-, VG10-, and VG11-sensitized photoelectrochemical cells, respectively.

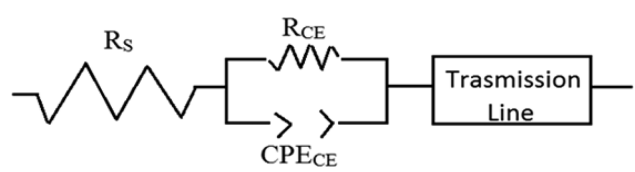

Figure 8. Equivalent circuit employed for the interpolation of the EIS data in Figure 7.

$\left(R_{\mathrm{s}}\right)$ that collects all resistive contributions arising from the electrical contacts, the external circuit, and the resistance of the FTO substrate of the photoelectrode; (ii) the interfacial element referring to the electron transfer process at the counterelectrode/electrolyte interface and defined as the parallel combination of the charge transfer resistance $\left(R_{\mathrm{CE}}\right)$ through the interface and a capacitance $\left(C_{\mathrm{CE}}\right)$ of the electrochemical double layer; (iii) the element of transmission line (TL) which comprises diffusion-recombination effects within the dye-sensitized photoelectrode and the capacitance associated with the sensitized $\mathrm{NiO}$ /electrolyte interface under illumination. The TL element takes into account the mesoporous nature of the semiconducting $\mathrm{NiO}$ layer, its thickness, and its hole transport properties. The latter properties are limited by the phenomenon of recombination and are controlled by the phenomenon of diffusion. Diffusion, in turn, originates from the existence of a chemical capacitance, i.e., a charge concentration gradient, ${ }^{87}$ within the mesoporous layer of $\mathrm{NiO}$ as customarily assumed for the photoactive electrodes of DSCs with typically discontinuous electronic structure. ${ }^{6}$ The EI spectra have been determined within a range of applied potential centered at $V_{\mathrm{OC}}$ and were varied $\pm 20 \mathrm{mV}$ around $V_{\mathrm{OC}}$ (vide infra). This procedure was followed with the aim of evaluating the response of the devices under changing operative conditions. The fitting curves obtained with the equivalent circuit of Figure 8 are shown in Figure ESI10. In the TL element of Figure 8, i.e., the circuital element referring to the electrochemical processes localized on the photoactive $\mathrm{NiO}$ cathode, the parameters of hole transport resistance $\left(R_{\mathrm{t}}\right)$ through the $\mathrm{NiO}$ layer, the photocharge transfer resistance across the $\mathrm{NiO} /$ electrolyte interface $\left(R_{\text {rec }}\right)$, and the chemical capacitance $C_{\mu}$ are enclosed. The latter is related to the capacitance $C_{\mathrm{CPE}}$ of the $\mathrm{CPE}$ (constant phase element) via the relationship $C_{\mu}=\left(C_{\mathrm{CPE}} * R_{\mathrm{rec}}\right)^{1 / n} / R_{\mathrm{rec}}$ the capacitance $C_{\mathrm{CPE}}$ and the dimensionless parameter $n$ being two fitting parameters. ${ }^{86,87}$
Fitting curves were evaluated with the $\chi^{2}$ test that gave a value smaller than $2 \times 10^{-4}$.

The transport resistance $R_{\mathrm{t}}$ follows approximately a trend opposite to that of the overall efficiency (see Table 1). This is equivalent to saying that the $p$-DSC with the largest value of $R_{t}$ presents the lowest value of $\eta$ and vice versa. This correlation combines with the direct proportionality which has been observed between $\eta$ and $J_{S C}$, the latter parameter being inversely proportional to $R_{\mathrm{t}}$. At the microscopic level the lower the transport resistance through $\mathrm{NiO}$, the higher the product $n^{\prime} u=\rho / e$, where $n^{\prime}, u, \rho$, and $e$ represent the charge carrier concentration (in $\mathrm{cm}^{-3}$ ), the charge carrier mobility (in $\mathrm{cm}^{2} \mathrm{~V}^{-1} \mathrm{~s}^{-1}$ ), the $\mathrm{NiO}$ photoconductivity (in $\mathrm{S} \mathrm{cm}{ }^{-1}$ ), and the elementary charge $\left(1.6 \times 10^{-19} \mathrm{C}\right)$, respectively. For NiO-based $p$-DSCs the increase of $J_{S C}$ accompanying the augmentation of $\eta$ is generally determined by the increase of the photoinjected holes concentration $\left(n^{\prime}\right.$ term) rather than by the increase of the holes mobility $(u$ term $) .^{70}$

The other charge transport parameter $R_{\mathrm{rec}}$ is inversely proportional to $\eta$ (confront Tables 1 and 2). Different from $R_{v}$

Table 2. Values of the Fitting Parameters $R_{\mathrm{v}}, R_{\text {rec }}$, and $C_{\mu}$ Contained in the TL Element of Figure 8 for Simulation of the Electrochemical Impedance Spectra Determined at Open-Circuit Potential (Figure 7)

\begin{tabular}{lcrr}
\multicolumn{1}{c}{ dye } & $R_{\mathrm{t}}(\Omega)$ & \multicolumn{1}{c}{$R_{\text {rec }}(\Omega)$} & \multicolumn{1}{c}{$C_{\mu}(\mu \mathrm{F})$} \\
ERY & $29.2 \pm 0.7$ & $124.2 \pm 1.1$ & $220 \pm 4$ \\
VG10-C8 & $48.8 \pm 2.5$ & $264.9 \pm 8.5$ & $66 \pm 3$ \\
VG 11-C8 & $28.6 \pm 2.4$ & $85.8 \pm 6.8$ & $60 \pm 8$ \\
\hline
\end{tabular}

the resistive term $R_{\text {rec }}$ depends on the rate of the bimolecular process of recombination between the photoinjected charges localized at the $\mathrm{NiO}$ electrode surface and iodide, i.e., the product of photoreduction. The lowest $R_{\text {rec }}$ value determined for the cell displaying the most efficacious photoconversion process, i.e., the VG11-sensitized p-DSC, is a straightforward consequence of the more efficient hole injection in VG11sensitized $\mathrm{NiO}$ with respect to the other sensitized systems. Upon illumination VG11 sensitizer injects a larger number of holes with respect to the other sensitizers here examined as evinced from efficiency data (Table 1). The presence of a relatively large surface concentration of holes $h^{+}$will favor their recombination with iodide since the latter process is a bimolecular event, the rate of which is directly proportional to the product $\left[\mathrm{I}^{-}\right]_{\text {interf }}\left[h^{+}\right]_{\text {interf }}$ at the $\mathrm{NiO} /$ electrolyte interface. ${ }^{70}$ Therefore, the faster holes-iodide recombination occurring in VG11-C8 sensitized p-DSC will correspond to the lowest $R_{\text {rec }}$ with respect to the less efficient colorants VG10 and ERY. The $p$-DSC sensitized with VG10 presented the highest value of $R_{\text {rec }}$ coherently with the finding of the largest $V_{\text {OC }}$ for this cell (Table 1 ). The $p$-DSC sensitized with ERY showed a much higher value of $C_{\mu}(220$ vs $66 \mu \mathrm{F}$, Table 2) compared to the SQ-sensitized counterparts. Such a finding could be associated with the spontaneous process of charge transfer between ERY dye and metal oxide ${ }^{88}$ even in the absence of polarization (or illumination) with consequent formation of larger gradients of charge carriers concentrations in screen-printed $\mathrm{NiO}$ with respect to the other SQ colorants (Figure ESI9). As stated in the preceding section, the phenomenon of charge transfer between sensitizer and oxide in the unbiased state of the $p$-DSC could be also at the basis of the observed behavior of ERY as a redox mediator in the 
Table 3. Values of the Parameters Related to Charge Carriers Features in $p$-DSCs ${ }^{a}$

\begin{tabular}{lcccc}
\multicolumn{1}{c}{ dye } & $\tau_{\mathrm{d}}(\mathrm{ms})$ & $\tau_{\mathrm{h}}(\mathrm{ms})$ & $D_{\mathrm{h}}\left(10^{-6} \mathrm{~cm}^{2} \mathrm{~s}^{-1}\right)$ & $L_{\mathrm{h}}(\mu \mathrm{m})$ \\
ERY & $6.40 \pm 0.27$ & $27.30 \pm 0.74$ & $26.52 \pm 3.22$ & $4.12 \pm 0.04$ \\
VG10-C8 & $2.73 \pm 0.29$ & $14.83 \pm 0.56$ & $79.54 \pm 2.56$ & $4.66 \pm 0.04$ \\
VG11-C8 & $1.71 \pm 0.37$ & $5.15 \pm 0.55$ & $70.00 \pm 5.49$ & $3.46 \pm 0.01$
\end{tabular}

${ }^{a}$ Listed data were calculated from eqs $1-4$ utilizing the fitting data reported in Table 2.

electron transfer process between $\mathrm{NiO}$ and triiodide in dark conditions (Figure ESI9 and Table ESI3). The parameters related to the properties of the positive charge carriers in $\mathrm{NiO}$, i.e., hole diffusion time $\tau_{\mathrm{d}}$, hole lifetime $\tau_{\mathrm{h}}$, diffusion length $L_{\mathrm{h}}$, and hole diffusion coefficient $D_{\mathrm{h}}$, can be derived from the fitting parameters $R_{\text {red }}, R_{\mathrm{v}}$, and $C_{\mu}$ reported in Table 2 through the relationships ${ }^{89}$

$$
\begin{aligned}
& \tau_{\mathrm{d}}=R_{\mathrm{t}} C_{\mu} \\
& \tau_{\mathrm{h}}=R_{\mathrm{rec}} C_{\mu} \\
& D_{\mathrm{h}}=L_{\mathrm{h}}^{2} / \tau_{\mathrm{d}}=L_{\mathrm{h}}^{2} /\left(R_{\mathrm{t}} C_{\mu}\right) \\
& L_{\mathrm{h}}=l\left(R_{\mathrm{rec}} / R_{\mathrm{t}}\right)^{1 / 2}
\end{aligned}
$$

The meaning of $\tau_{\mathrm{d}}$ is the time the photoinjected hole spends to reach the current collector by diffusion, $\tau_{\mathrm{h}}$ is the lifetime of the photoinjected hole prior to undergoing recombination or charge trapping phenomena, $D_{\mathrm{h}}$ is the diffusion coefficient of the photoinjected hole within the $\mathrm{NiO}$ layer, $L_{\mathrm{h}}$ is the diffusion distance covered by the photohole before incurring recombination phenomena, and $l$ is the $\mathrm{NiO}$ film thickness in eq 4 .

The most efficient photoelectrochemical cell with VG11 as colorant presented smaller temporal parameters $\tau_{\mathrm{d}}$ and $\tau_{\mathrm{h}}$ as a consequence of the lowest values of the two resistive terms $R_{\mathrm{t}}$ and $R_{\text {rec }}$ among the cells here tested (Table 2). The VG11sensitized cell presented also the largest diffusion coefficient for the photoinjected holes (Table 3 ), since in this case the $D_{\mathrm{h}}$ value was principally controlled by the short time of transport diffusion $\tau_{\mathrm{d}}$ (eq 3 ) but less by $L_{\mathrm{h}}$ through the ratio $R_{\mathrm{rec}} / R_{\mathrm{t}}$ (eq 4 ). The latter parameter was not strongly dependent on the nature of the dye (see the first column on the right of Table 3).

The ERY-based device displayed higher values of $\tau_{\mathrm{d}}$ and $\tau_{\mathrm{h}}$ for the hole carriers due to the largest value of chemical capacitance (first column on the right of Table 2, eqs 1 and 2). For the $p$-DSCs sensitized with VG10, VG11, and ERY the respective diffusion lengths of the hole carriers were always larger than the nominal thickness of the $\mathrm{NiO}$ film $(l=2 \mu \mathrm{m})$. The latter condition is necessary but not sufficient to realize an efficient process of charge collection at the $\mathrm{FTO} / \mathrm{NiO}$ interface since in a nanoporous film like the ones of $\mathrm{NiO}$ here considered the hole pathways are generally not linear. As a consequence, the distance the hole actually travels before it reaches the collection surface could be much longer than the value of $\mathrm{NiO}$ film thickness determined with the profilometer.

In the EIS study here presented we considered also the determination of the impedance spectra for the three $p$-DSCs analyzed in Figure 7 when the applied potential of the steady state was varied within a range of $40 \mathrm{mV}$ around the opencircuit photopotential (see caption of Figure 7). The trends of the three fitting parameters $R_{\mathrm{rec}}, R_{\mathrm{v}}$ and $C_{\mu}$ with the variation of the applied potential of steady state are shown in Figure 9, whereas the correlated properties of $\tau_{\mathrm{d}}, \tau_{\mathrm{h}}, L_{\mathrm{h}}$, and $D_{\mathrm{h}}$ calculated through eqs $1-4$ for the positive charge carriers of $\mathrm{NiO}$ are shown in Figure 10.
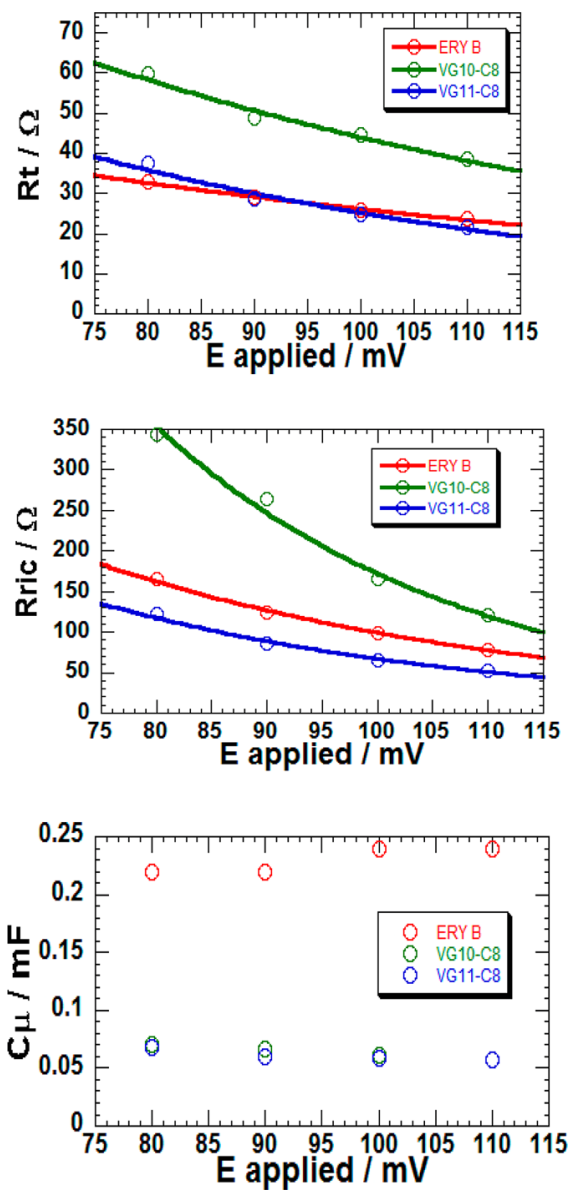

Figure 9. Variation of the fitting parameters (top) $R_{\mathrm{v}}$ (middle) $R_{\mathrm{rec}}$ and (bottom) $C_{\mu}$ defining the TL element in the model of equivalent circuit here proposed (Figure 8) with the variation of the potential of steady state applied on the three $p$-DSCs presented in Figure 7 . It is here recalled that $V_{\mathrm{OC}}$ values of the three $p$-DSCs in question were 100, 90, and $90 \mathrm{mV}$ for VG10-, VG11-, and ERY-sensitized $p$-DSC, respectively.

Every fitting parameter $R_{\mathrm{rec}}, R_{\mathrm{v}}$ and $C_{\mu}$ showed a similar trend within the range of applied steady-state potential here examined regardless of the nature of the dye (Figure 9). The chemical capacitance resulted in the parameter being less affected by the variation of applied potential around $V_{\mathrm{OC}}$ with the observation of the quasiconstancy of the $C_{\mu}$ value for a given dye sensitizer (Figure 9, bottom plot). The resistive terms $R_{\text {rec }}$ and $R_{\mathrm{t}}$ as well as the correlated characteristic times $\tau_{\mathrm{d}}$ and $\tau_{\mathrm{h}}$ (eqs 1 and 2, Figure 10) decreased upon increasing applied potential with respect to the open-circuit value because of the forward polarization of $\mathrm{NiO}$ which induces the injection of a larger number of photoholes with respect to the absence of polarization. ****Since $R_{\mathrm{rec}}$ decreases more steeply than $R_{\mathrm{t}}$ with the applied steady-state potential, the resulting trend of the diffusion length is the slow decrease of $L_{\mathrm{h}}$ with $E_{\text {appl }}$ (Figure 10 , bottom plot) with $L_{\mathrm{h}}$ always surpassing $l$ in the examined 

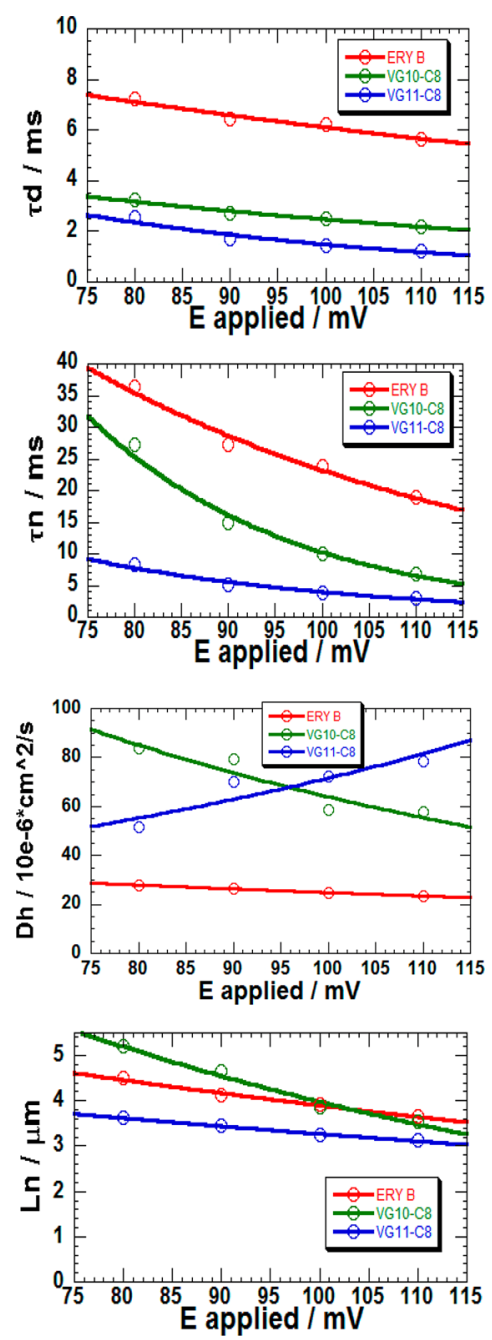

Figure 10. Potential dependence of the hole transport properties (top) $\tau_{\mathrm{d}}$ (second from top) $\tau_{\mathrm{h}}$ (third from top) $D_{\mathrm{h}}$, and (bottom) $L_{\mathrm{h}}$ calculated with eqs $1-4$ in the main text from the values of $R_{\mathrm{v}}, R_{\mathrm{rec}}$ and $C_{\mu}$ reported in Figure 9.

range of applied potential. In the sole case of VG11, the diffusion coefficient increased with the applied potential (Figure 10, third plot from top) mainly as a consequence of the decrease of the diffusion time $\tau_{\mathrm{d}}$ and $R_{\mathrm{v}}$ the latter resistive term representing the main controlling factor of the diffusion coefficient $D_{\mathrm{h}}$ of the photoinjected holes (combination of eqs 1 and 3 , vide supra).

Finally, we recorded the EI spectra (not shown) of the VG10- and VG11-sensitized $p$-DSCs when the sensitization solution contained the concentration ratios $[\mathrm{CDCA}]:[\mathrm{SQ}]=$ $0: 1,10: 1$, and 100:1. This set of experiments was carried out to analyze the effect of the antiaggregating agent CDCA on the transport and charge carrier parameters of VG10- and VG11sensitized $p$-DSCs. The electrochemical impedance spectra of the $p$-DSCs with the $\mathrm{NiO}$ cathodes sensitized in the solutions with $[\mathrm{CDCA}]:[\mathrm{SQ}]=1000: 1$ were not taken for the insignificance of their low efficiencies of conversion $(\eta<$ $0.02 \%$, Table 1 ). The variations of $R_{\mathrm{rec}}, R_{\mathrm{t}}$ and $C_{\mu}$ with the applied potential for the $p$-DSCs sensitized in differently concentrated CDCA solutions are presented in Figures ESI11 and ESI12. The corresponding variations of the hole transport properties $\tau_{\mathrm{d}}, \tau_{\mathrm{h}}, D_{\mathrm{h}}$, and $L_{\mathrm{h}}$ (eqs $1-4$ ) with the applied potential have been shown in Figures ESI13 and ESI14. The fitting parameters of the impedance spectra obtained with such CDCA-conditioned $p$-DSCs showed common trends of $R_{\mathrm{v}} R_{\mathrm{rec}}$ and $C_{\mu}$ with the applied potential $E_{\text {appl }}$ (Figures ESI11 and ESI12): all three parameters decrease with $E_{\text {appl }}$ as expected in a situation of forward bias no matter the value of sensitizing ratio [CDCA]:[SQ]. The resistive term $R_{\mathrm{t}}$ associated with the photocarriers transport through $\mathrm{NiO}$, was lowest for the most efficacious sensitizing ratio [CDCA]:[SQ] $(=10: 1)$. This is because in the absence of antiaggregating agent in the electrode dipping solution the eventual formation of dye aggregates occurs on the $\mathrm{NiO}$ surface, preventing efficacious photoinjection from the excited dye aggregates. At the other extreme, i.e., for a too high concentration of CDCA with respect to $S Q$ case of [CDCA]:[SQ] = 100:1, we would verify insufficient dye loading (Figure 4, black profiles) with poor charge injection and consequent higher transport resistance. In correspondence of the optimized sensitizing ratio $[\mathrm{CDCA}]:[\mathrm{SQ}]=10: 1$ (Table 1 and Figure ESI3) the term $R_{\mathrm{rec}}$ was the highest for VG10 and the lowest for VG11 among the various compositions of the sensitizing solution. Since the cell sensitized with VG11 generally displayed a higher conversion efficiency with respect to that with VG10 sensitizer (Table 1), we conclude here that the parameter $R_{\mathrm{rec}}$ is less crucial than $R_{\mathrm{t}}$ in determining the overall photocell performance.

At the optimized ratio [CDCA]:[SQ] $=10: 1, R_{\mathrm{t}}$ is generally lower for the best performing photoelectrochemical cell, i.e., the one employing VG11 sensitizer, whereas $C_{\mu}$ shows a very weak dependence on the nature of the SQ sensitizer (Figures ESI11 and ESI12). Since any capacitive term is directly proportional to the surface charge density and inversely proportional to charge separation, the relatively high values of $C_{\mu}$ for the best performing VG10- and VG11-sensitized $p$-DSCs have to be ascribed mostly to the amount of injected charge rather than to the spatial separation of charge which is mainly controlled by the size and orientation of the chemisorbed dyes (Figure 5). The latter consideration stems from the assumption that charge separation at the electrode/electrolyte is controlled by the size of the molecule and not by the capability of the counterions of the electrolyte to reach the charged portion of illuminated sensitized $\mathrm{NiO}$ surface. ${ }^{88}$ Therefore, we conclude here that the most efficacious processes of photoinjection will be generally accompanied by a relatively large capacitive term $C_{\mu}$ in the case of $p$-DSCs with SQ-sensitized $\mathrm{NiO}$ when $\mathrm{I}_{3}{ }^{-} / \mathrm{I}^{-}$ is the redox shuttle. As a confirmation, we stress that from the observation of $C_{\mu}$ trends (bottom plots of Figures ESI11 and ESI12), the capacitive term displayed the largest values at the optimized sensitizing ratio $[\mathrm{CDCA}]$ : $[\mathrm{SQ}]=10: 1$ for both $\mathrm{SQs}$ under examination. Therefore, a large value of $C_{\mu}$ could constitute a condition that accompanies an ameliorated performance for this type of photoelectrochemical cell. In the absence of any antiaggregating agent, the full dye sensitization of $\mathrm{NiO}$ produces a corresponding $p$-DSC with less efficacious injection with respect to the optimized one because of the presence of unwanted aggregates of dyes which do not allow a sufficiently fast hole injection in the photoexcited state with subsequent incapability of building up charge distributions with high surface concentration. On the other hand, too diluted surface concentrations of anchored dye, such as those obtained with $[\mathrm{CDCA}]:[\mathrm{SQ}] \geq 100: 1$ in the sensitizing solution, do not allow a sufficient injection of charge for the buildup of charge distributions with correspondingly high $C_{\mu}$ values. The discussion of the dependence of the microscopic parameters $\tau_{\mathrm{d}}, \tau_{\mathrm{h}}, D_{\mathrm{h}}$ and $L_{\mathrm{h}}$ of the $p$-DSCs employing VG10 and VG11 
sensitizers on the concentration of antiaggregating agent and applied potential (Figures ESI13 and ESI14) is reported in the ESI.

\section{CONCLUSIONS}

The three symmetric squaraines VG1, VG10, and VG11 of the $\mathrm{C} 8$ series, i.e., with an octyl group as pending $\mathrm{N}$ substituent of the indolenine moiety, have been used to sensitize screenprinted $\mathrm{NiO}$ photocathodes for $p$-DSCs. In particular, VG11 dye has been purposely designed for a $p$-DSC employing $\mathrm{I}_{3}^{-} / \mathrm{I}^{-}$ redox shuttle taking into account the rationale of introducing the dicyano-vinyl group as the electron-withdrawing chromophoric unit positioned far away from the $-\mathrm{COOH}$ unit which connects the dye to the $\mathrm{NiO}$ surface. This design was inspired by the analysis of the structural factors that were associated with the best performing dye sensitizers of $p$-DSCs with the predefined aim of accelerating the electron transfer process between photoexcited dye and the oxidized form of the redox shuttle as well with the intention of minimizing unwanted recombination phenomena between the holes photoinjected in $\mathrm{NiO}$ and the product of photoreduction $\mathrm{I}^{-}$when the sensitizer was a SQ.

The molecular design of squaraine VG11-C8 was inspired by the individuation of the function exerted by the different structural units of those dyes that constitute the best known and efficient sensitizers of $p$-DSCs. It has been proven with electrochemical and photoelectrochemical techniques that the electron-attracting dicyano-vinyl group at the central core of VG11 and located in a position opposite to the site of anchoring imparted a stronger directionality of the net electron transfer from $\mathrm{NiO}$ to triiodide mediated by photoexctited VG11 with respect to the other two SQs deprived of an electron-withdrawing substituent. Therefore, the structure of VG11 produced favorable effects on the kinetics of dyemediated electron transfer between the semiconductor and the redox mediator as evinced from a comparative analysis of the electrochemical impedance data of the variously sensitized $p$ DSCs. The benzo-indoleninic unit of VG10 and VG11, i.e., the most extended conjugated spacer here considered, was identified as the structural moiety at the basis of the relatively slower process of recombination of VG10 and VG11 vs VG1 in conditions of open-circuit potential and steady-state polarization. The latter conclusion was evinced from the modeling of the photoelectrochemical impedance data of the corresponding $p$-DSCs, which allowed calculation of the transport parameters $R_{\text {rec }}$ and $R_{\mathrm{t}}$ and the derived microscopic parameters $\tau_{\mathrm{d}}, \tau_{\mathrm{h}}$, and $D_{\mathrm{h}}$. Therefore, it was found that the larger size of VG10 and VG11 had a beneficial effect on the overall conversion efficiencies in the corresponding $p$-DSCs. The photoelectrochemical cells with the largest efficiencies were those displaying the lowest charge transport resistance $R_{\mathrm{t}}$ (a parameter correlated to the amount and mobility of photoinjected charge) and the lowest recombination resistance $R_{\text {rec }}$ (a parameter correlated to the amount and lifetime of the photoinjected charge), with $R_{\mathrm{t}}$ being more crucial than $R_{\text {rec }}$ for achievement of the largest efficiencies. VG11 gave $p$-DSCs with maximum overall efficieny of $0.043 \%$ which represents, to our knowledge, the highest value of efficiency ever reported for a symmetric squaraine sensitizing a $p$-DSCs when the squaraine is the sole chromophoric unit of the sensitizer and $\mathrm{I}_{3}^{-} / \mathrm{I}^{-}$is the electrolyte mediator. Sensitization of screen-printed $\mathrm{NiO}$ with the three SQs here proposed has been conducted also in the presence of CDCA, i.e., an antiaggregating agent preventing intermolecular interactions between the dyes chemisorbed on the electrode surface. CDCA was an ameliorant of the photoelectrochemical performances of the SQs-sensitized p-DSCs when the molar ratio $[\mathrm{CDCA}]:[\mathrm{SQ}]$ in the solution of sensitization had an optimum value of 10:1 with an increase of overall efficiencies of about $25 \%$ with respect to CDCA-free sensitization treatments. This was ascribed to kinetic competition between CDCA and SQ for the occupancy of the allotted sites of anchoring on $\mathrm{NiO}$ surface. A hypothesis of the geometry of SQ anchoring has been here proposed for the different systems taking into account how the carboxylic units were relatively oriented in the structure of these three symmetric SQs. Another aim of this work is the attempt of laying the foundation for further improvement of $p$-DSC performances through the proper design of SQ sensitizers as the main focus of $p$-DSC optimization.

\section{ASSOCIATED CONTENT}

\section{Supporting Information}

The Supporting Information is available free of charge on the ACS Publications website at DOI: 10.1021/acs.jpcc.6b03965.

Paste synthetic path and dye characterization; in-depth and useful electrochemical impedance analysis; most important new hypothesis discussed in the main text (PDF) Additional figures (PDF)

\section{AUTHOR INFORMATION}

\section{Corresponding Authors}

*Phone: +39 0116707596/5323. Fax +39 0116707591. E-mail claudia.barolo@unito.it.

*Phone: +39 0649913335. Fax: +39 06490324. E-mail danilo. dini@uniroma1.it.

\section{Notes}

The authors declare no competing financial interest.

\section{ACKNOWLEDGMENTS}

The authors acknowledge the financial support from MIUR which funded the research project PRIN 2010-2011 (protocol no. 20104XET32). D.D. acknowledges the financial support from the University of Rome "LA SAPIENZA" through the program Ateneo 2012 (Protocol No. C26A124AXX). D.D. thanks Dr. Andrea G. Marrani of the Department of Chemistry at the University of Rome "LA SAPIENZA" for the profitable discussions on the appropriate use of surface techniques for characterization of photoactive electrode surfaces of dyesensitized solar cells. A.D.C. thanks Regione Lazio and CHOSE for the technical support of the research conducted at the University of Rome "Tor Vergata".

\section{REFERENCES}

(1) Hagfeldt, A.; Boschloo, G.; Sun, L.; Kloo, L.; Pettersson, H. Dyesensitized solar cells. Chem. Rev. 2010, 110, 6595-6663.

(2) Green, M. A.; Emery, K.; Hishikawa, Y.; Warta, W.; Dunlop, E. D. Solar cell efficiency tables (version 43). Prog. Photovoltaics 2014, 22, $1-9$.

(3) Desilvestro, H.; Bertoz, M.; Tulloch, S.; Tulloch, G. Packaging, scale-up and commercialization of dye solar cells. In Dye-Sensitized Solar Cells (Fundamental Sciences Series, Chemistry); Kalyanasundaram, K., Ed.; EPFL Press-CRC: Lausanne, 2010; pp 207-249.

(4) Gerischer, H.; Michel-Beyerle, M. E.; Rebentrost, F.; Tributsch, $\mathrm{H}$. Sensitization of charge injection into semiconductors with large band gap. Electrochim. Acta 1968, 13, 1509-1515. 
(5) Liska, P.; Vlachopoulos, N.; Nazeeruddin, M. K.; Comte, P.; Grätzel, M. Cis-diaquabis (2,2' -bipyridyl-4,4'-dicarboxylate)ruthenium(II) sensitizes wide band gap oxide semiconductors very efficiently over a broad spectral range in the visible. J. Am. Chem. Soc. 1988, 110, 3686-3687.

(6) Hagfeldt, A.; Grätzel, M. Light-induced redox reactions in nanocrystalline systems. Chem. Rev. 1995, 95, 49-68.

(7) Nazeeruddin, M. K.; Kay, A.; Rodicio, I.; Humphry-Baker, R.; Müller, E.; Liska, P.; Vlachopoulos, N.; Grätzel, M. Conversion of light to electricity by cis- $\mathrm{X}_{2} \mathrm{Bis}\left(2,2^{\prime}\right.$-bipyridyl-4,4'-dicarboxylate)ruthenium(II) charge-transfer sensitizers $\left(\mathrm{X}=\mathrm{Cl}^{-}, \mathrm{Br}^{-}, \mathrm{I}^{-}, \mathrm{CN}^{-}\right.$, and $\left.\mathrm{SCN}^{-}\right)$on nanocrystalline $\mathrm{TiO}_{2}$ electrodes. J. Am. Chem. Soc. 1993, 115, 63826390.

(8) Grätzel, M. Perspectives for dye-sensitized nanocrystalline solar cells. Prog. Photovoltaics 2000, 8, 171-185.

(9) Grätzel, M. Photoelectrochemical cells. Nature 2001, 414, 338344.

(10) Boschloo, G.; Hagfeldt, A. Characteristics of the iodide/triiodide redox mediator in dye-sensitized solar cells. Acc. Chem. Res. 2009, 42, $1819-1826$

(11) Frank, A.; Kopidakis, N.; Van de Lagemaat, J. Electrons in nanostructured $\mathrm{TiO}_{2}$ solar cells: transport, recombination and photovoltaic properties. Coord. Chem. Rev. 2004, 248, 1165-1179.

(12) Cameron, P. J.; Peter, L. M.; Zakeeruddin, S. M.; Grätzel, M. Electrochemical studies of the $\mathrm{Co}(\mathrm{III}) / \mathrm{Co}(\mathrm{II})$ (dbbip) ${ }_{2}$ redox couple as a mediator for dye-sensitized nanocrystalline solar cells. Coord. Chem. Rev. 2004, 248, 1447-1453.

(13) Nattestad, A.; Ferguson, M.; Kerr, R.; Cheng, Y. B.; Bach, U. Dye-sensitized nickel(II)oxide photocathodes for tandem solar cell applications. Nanotechnology 2008, 19, 295304.

(14) Kakiage, K.; Aoyama, Y.; Yano, T.; Oya, K.; Fujisawa, J. I.; Hanaya, M. Highly-efficient dye-sensitized solar cells with collaborative sensitization by silyl-anchor and carboxy-anchor dyes. Chem. Commun. 2015, 51, 15894-15897.

(15) Bonomo, M.; Dini, D. Nanostructured p-type semiconductor electrodes and photoelectrochemistry of their reduction processes. Energies 2016, 9, 373.

(16) Li, M. H.; Yum, J. H.; Moon, S. J.; Chen, P. Inorganic p-type semiconductors: their applications and progress in dye-sensitized solar cells and perovskite solar cells. Energies 2016, 9, 331.

(17) Dini, D. Nanostructured metal oxide thin films as photoactive cathodes of p-type dye- sensitised solar cells. Phys. Chem. Commun. 2016, 3, 14-51.

(18) Dini, D.; Halpin, Y.; Vos, J. G.; Gibson, E. A. The influence of the preparationmethod of $\mathrm{NiO}_{\mathrm{x}}$ photocathodes on the efficiency of $\mathrm{p}$ type dye-sensitized solar cells. Coord. Chem. Rev. 2015, 304-305, 179-201.

(19) Wood, C. J.; Summers, G. H.; Clark, C. A.; Kaeffer, N.; Braeutigam, M.; Carbone, L. R.; D’Amario, L.; Fan, K.; Farré, Y.; Narbey, S.; et al. A comprehensive comparison of dye-sensitized $\mathrm{NiO}$ photocathodes for solar energy conversion. Phys. Chem. Chem. Phys. 2016, 18, 10727-10738.

(20) Daeneke, T.; Yu, Z.; Lee, G. P.; Fu, D.; Duffy, N. W.; Makuta, S.; Tachibana, Y.; Spiccia, L.; Mishra, A.; Bäuerle, P.; Bach, U. Dominating energy losses in NiO p-type dye-sensitized solar cells. Adv. Energy Mater. 2015, 5, 1401387.

(21) Nattestad, A.; Mozer, A. J.; Fischer, M. K. R.; Cheng, Y. B.; Mishra, A.; Bäuerle, P.; Bach, U. Highly efficient photocathodes for dye-sensitized tandem solar cells. Nat. Mater. 2010, 9, 31-35.

(22) Qin, P.; Zhu, H.; Edvinsson, T.; Boschloo, G.; Hagfeldt, A.; Sun, L. Design of an organic chromophore for p-type dye-sensitized solar cells. J. Am. Chem. Soc. 2008, 130, 8570-8571.

(23) Wu, M. S.; Wang, M. J. Nickel oxide film with open macropores fabricated by surfactant- assisted anodic deposition for high capacitance supercapacitors. Chem. Commun. 2010, 46, 6968-6970.

(24) Powar, S.; Daeneke, T.; Ma, M. T.; Fu, D.; Duffy, N. W.; Götz, G.; Weidelener, M.; Mishra, A.; Bäuerle, P.; Spiccia, L.; Bach, U. Highly efficient p-type dye-sensitized solar cells based on tris $(1,2-$
diaminoethane)cobalt(II)/(III) electrolytes. Angew. Chem., Int. Ed. 2013, 52, 602-605.

(25) Bella, F.; Galliano, S.; Gerbaldi, C.; Viscardi, G. Cobalt-based electrolytes for dye-sensitised solar cells: recent advances towards stable devices. Energies 2016, 9, 384.

(26) Awais, M.; Dowling, D. D.; Decker, F.; Dini, D. Photoelectrochemical properties of mesoporous $\mathrm{NiO}_{\mathrm{x}}$ deposited on technical FTO via nanopowder sintering in conventional and plasma atmospheres. SpringerPlus 2015, 4, 564.

(27) Tachiki, M.; Hosomi, T.; Kobayashi, T. Room-temperature heteroepitaxial growth of $\mathrm{NiO}$ thin films using pulsed laser deposition. Jpn. J. Appl. Physics, Part 1 2000, 39, 1817-1820.

(28) Naponiello, G.; Venditti, I.; Zardetto, V.; Saccone, D.; Di Carlo, A.; Fratoddi, I.; Barolo, C.; Dini, D. Photoelectrochemical characterization of squaraine-sensitized nickel oxide cathodes deposited via screen-printing for p-type dye-sensitized solar cells. Appl. Surf. Sci. 2015, 356, 911-920.

(29) Awais, M.; Rahman, M.; MacElroy, J. M. D.; Coburn, N.; Dini, D.; Vos, J. G.; Dowling, D. P. Deposition and characterization of $\mathrm{NiO}_{x}$ coatings by magnetron sputtering for application in dye-sensitized solar cells. Surf. Coat. Technol. 2010, 204, 2729-2736.

(30) Bonomo, M.; Naponiello, G.; Di Carlo, A.; Dini, D. Characterization of screen-printed nickel oxide electrodes for $p$-type dye-sensitized solar cells. J. Mater. Sci. Nanotechnol. 2016, 4, 201.

(31) Odobel, F.; Le Pleux, L.; Pellegrin, Y.; Blart, E. New photovoltaic devices based on the sensitization of p-type semiconductors: challenges and opportunities. Acc. Chem. Res. 2010, 43, $1063-1071$

(32) He, J.; Lindström, H.; Hagfeldt, A.; Lindquist, S. E. Dyesensitized nanostructured tandem cell-first demonstrated cell with a dye-sensitized photocathode. Sol. Energy Mater. Sol. Cells 2000, 62, 265-273.

(33) Barbero, N.; Magistris, C.; Park, J.; Saccone, D.; Quagliotto, P.; Buscaino, R.; Medana, C.; Barolo, C.; Viscardi, G. Microwave-assisted synthesis of near-infrared fluorescent indole-based squaraines. Org. Lett. 2015, 17, 3306-3309.

(34) Tatarets, A. L.; Fedyunyaeva, I. A.; Terpetschnig, E.; Patsenker, L. D. Synthesis of novel squaraine dyes and their intermediates. Dyes Pigm. 2005, 64, 125-134.

(35) Saccone, D.; Galliano, S.; Barbero, N.; Quagliotto, P.; Viscardi, G.; Barolo, C. Polymethine dyes in hybrid photovoltaics: structureproperties relationships. Eur. J. Org. Chem. 2016, 2016, 2244-2259.

(36) Beverina, L.; Sassi, M. Twists and Turns Around a Square: the Many Faces of Squaraine Chemistry. Synlett 2014, 25, 477-490.

(37) Chen, G.; Sasabe, H.; Igarashi, T.; Hong, Z.; Kido, J. Squaraine dyes for organic photovoltaic cells. J. Mater. Chem. A 2015, 3, 1451717534.

(38) Barolo, C.; Yum, J. H.; Artuso, E.; Barbero, N.; Di Censo, D.; Lobello, M. G.; Fantacci, S.; De Angelis, F.; Grätzel, M.; Nazeeruddin, M. K.; Viscardi, G. A simple synthetic route to obtain pure transruthenium(II) complexes for dye-sensitized solar cell applications. ChemSusChem 2013, 6, 2170-2180.

(39) Kanaparthi, R. K.; Kandhadi, J.; Giribabu, L. Metal-free organic dyes for dye-sensitized solar cells: recent advances. Tetrahedron 2012, $68,8383-8393$

(40) Magistris, C.; Martiniani, S.; Barbero, N.; Park, J.; Benzi, C.; Anderson, A.; Law, C. H.; Barolo, C.; O’Regan, B. Near-infrared absorbing squaraine dye with extended $\pi$ conjugation for dyesensitized solar cells. Renewable Energy 2013, 60, 672-678.

(41) Park, J.; Viscardi, G.; Barolo, C.; Barbero, N. Near-infrared sensitization in dye-sensitized solar cells. Chimia 2013, 67, 129-135.

(42) Venditti, I.; Barbero, N.; Russo, M. V.; Di Carlo, A.; Decker, F.; Fratoddi, I.; Barolo, C.; Dini, D. Electrodeposited $\mathrm{ZnO}$ with squaraine sentisizers as photoactive anode of DSCs. Mater. Res. Express 2014, 1, 015040 .

(43) Rao, G. H.; Venkateswararao, A.; Giribabu, L.; Singh, S. P. Nearinfrared unsymmetrical blue and green squaraine sensitizers. Photochem. Photobiol. Sci. 2016, 15, 287-296. 
(44) Shi, Y.; Hill, R. B. M.; Yum, J. H.; Dualeh, A.; Barlow, S.; Grätzel, M.; Marder, S. R.; Nazeeruddin, M. K. A high-efficiency panchromatic squaraine sensitizer for dye-sensitized solar cells. Angew. Chem., Int. Ed. 2011, 50, 6619-6621.

(45) Chang, C. H.; Chen, Y. C.; Hsu, C. Y.; Chou, H. H.; Lin, J. T. Squaraine-arylamine sensitizers for highly efficient p-type dyesensitized solar cells. Org. Lett. 2012, 14, 4726-4729.

(46) Park, J.; Barolo, C.; Sauvage, F.; Barbero, N.; Benzi, C.; Quagliotto, P.; Coluccia, S.; Di Censo, D.; Grätzel, M.; Nazeeruddin, M. K.; Viscardi, G. Symmetric vs asymmetric squaraines as photosensitisers in mesoscopic injection solar cells: a structureproperty realtionship study. Chem. Commun. 2012, 48, 2782-2784.

(47) Yum, J. H.; Moon, S. J.; Humphry-Baker, R.; Walter, P.; Geiger, T.; Nüesch, F.; Grätzel, M.; Nazeeruddin, M. K. Effect of coadsorbent on the photovoltaic performance of squaraine sensitized nanocrystalline solar cells. Nanotechnology 2008, 19, 424005.

(48) Daeneke, T.; Kwon, T. K.; Holmes, A. B.; Duffy, N. W.; Bach, U.; Spiccia, L. High-efficiency dye-sensitized solar cells with ferrocenebased electrolytes. Nat. Chem. 2011, 3, 211-215.

(49) Salvatori, P.; Marotta, G.; Cinti, A.; Anselmi, C.; Mosconi, E.; De Angelis, F. Supramolecular interactions of chenodeoxycholic acid increase the efficiency of dye-sensitized solar cells based on a cobalt electrolyte. J. Phys. Chem. C 2013, 117, 3874-3887.

(50) He, J.; Lindström, H.; Hagfeldt, A.; Lindquist, S. E. Dyesensitized nanostructured p-type nickel oxide film as a photocathode for a solar cell. J. Phys. Chem. B 1999, 103, 8940-8943.

(51) Awais, M.; Dowling, D. P.; Rahman, M.; Vos, J. G.; Decker, F.; Dini, D. Spray-deposited $\mathrm{NiO}_{\mathrm{x}}$ films on ITO substrates as photoactive electrodes for p-type dye-sensitized solar cells. J. Appl. Electrochem. 2013, 43, 191-197.

(52) Awais, M.; Gibson, E.; Vos, J. G.; Dowling, D. P.; Hagfeldt, A.; Dini, D. Fabrication of efficient $\mathrm{NiO}$ photocathodes prepared via $\mathrm{RDS}$ with novel routes of substrate processing for p-type dye-sensitized solar cells. ChemElectroChem 2014, 1, 384-391.

(53) Awais, M.; Dowling, D. P.; Decker, F.; Dini, D. Electrochemical characterization of nanoporous nickel oxide thin films spray-deposited onto indium-doped tin oxide for solar conversion scopes. $A d v$. Condens. Matter Phys. 2015, 2015, 186375.

(54) Pumiglia, D.; Giustini, M.; Dini, D.; Decker, F.; Lanuti, A.; Mastroianni, S.; Veyres, S.; Caprioli, F. Photoelectrochemical response of DSSCs under prolonged reverse bias and conduction band lowering in Ru-complex-sensitized $\mathrm{TiO}_{2}$. ChemElectroChem 2014, 1, 13881394.

(55) Fabregat-Santiago, F.; Bisquert, J.; Garcia-Belmonte, G.; Boschloo, G.; Hagfeldt, A. Influence of electrolyte in tran sport and recombination in dye-sensitized solar cells studied by impedance spectroscopy. Sol. Energy Mater. Sol. Cells 2005, 87, 117-131.

(56) Fabregat-Santiago, F.; Garcia-Belmonte, G.; Mora-Sero, I.; Bisquert, J. Characterization of nanostructured hybrid and organic solar cells by impedance spectroscopy. Phys. Chem. Chem. Phys. 2011, 13, 9083-9118.

(57) Bisquert, J. Influence of the boundaries in the impedance of porous film electrodes. Phys. Chem. Chem. Phys. 2000, 2, 4185-4192.

(58) Bisquert, J. Theory of impedance of charge transfer via surface states in dye-sensitized solar cells. J. Electroanal. Chem. 2010, 646, 4351.

(59) Bisquert, J.; Bertoluzzi, L.; Mora-Sero, I.; Garcia-Belmonte, G. Theory of impedance and capacitance spectroscopy of solar cells with dielectric relaxation, drift-diffusion transport, and recombination. $J$. Phys. Chem. C 2014, 118, 18983-18991.

(60) Gibson, E. A.; Awais, M.; Dini, D.; Dowling, D. P.; Pryce, M. T.; Vos, J. G.; Boschloo, G.; Hagfeldt, A. Dye sensitised solar cells with nickel oxide photocathodes prepared via scalable microwave sintering. Phys. Chem. Chem. Phys. 2013, 15, 2411-2420.

(61) Ito, S.; Chen, P.; Comte, P.; Nazeeruddin, M. K.; Liska, P.; Pechy, P.; Grätzel, M. Fabrication of screen-printing pastes from $\mathrm{TiO}_{2}$ powders for dye-sensitised solar cells. Prog. Photovoltaics 2007, 15, $603-612$.
(62) Li, L.; Gibson, E. A.; Qin, P.; Boschloo, G.; Gorlov, M.; Hagfeldt, A.; Sun, L. Double-layered $\mathrm{NiO}$ photocathodes for p-type DSSCs with record IPCE. Adv. Mater. 2010, 22, 1759-1762.

(63) Zhang, X. L.; Huang, F.; Nattestad, A.; Wang, K.; Fu, D.; Mishra, A.; Bauerle, P.; Bach, U.; Cheng, Y. B. Enhanced open-circuit voltage of p-type DSC with highly crystalline $\mathrm{NiO}$ nanoparticles. Chem. Commun. 2011, 47, 4808-4810.

(64) Zhang, X. L.; Zhang, Z.; Chen, D.; Bauerle, P.; Bach, U.; Cheng, Y. B. Sensitization of nickel oxide: improved carrier lifetime and charge collection by tuning nano scale crystallinity. Chem. Commun. 2012, 48, 9885-9887.

(65) Awais, M.; Rahman, M.; Don MacElroy, J. M.; Dini, D.; Vos, J. G.; Dowling, D. P. Application of a novel microwave plasma treatment for the sintering of nickel oxide coatings for use in dye-sensitized solar cells. Surf. Coat. Technol. 2011, 205, S245-S249.

(66) Marrani, A. G.; Novelli, V.; Sheehan, S.; Dowling, D. P.; Dini, D. Probing the redox states at the surface of electroactive nanoporous $\mathrm{NiO}$ thin films. ACS Appl. Mater. Interfaces 2014, 6, 143-152.

(67) Galliano, S.; Novelli, V.; Barbero, N.; Smarra, A.; Viscardi, G.; Borrelli, R.; Sauvage, F.; Barolo, C. Dicyanovinyl and cyano-ester squaraine dyes: the effect of the central functionalization on the DSCs performances. Energies 2016, 9, 486.

(68) De Rossi, F.; Di Gaspare, L.; Reale, A.; Di Carlo, A.; Brown, T. M. Blending $\mathrm{CoS}$ and $\mathrm{Pt}$ for amelioration of electrodeposited transparent counterelectrodes and the efficiency of back-illuminated dye solar cells. J. Mater. Chem. A 2013, 1, 12941-12947.

(69) Borgström, M.; Blart, E.; Boschloo, G.; Mukhtar, E.; Hagfeldt, A.; Hammarstrom, L.; Odobel, F. Sensitized hole injection of phosphorus porphyrin into $\mathrm{NiO}$ : toward new photovoltaic devices. J. Phys. Chem. B 2005, 109, 22928-22934.

(70) Sheehan, S.; Naponiello, G.; Odobel, F.; Dowling, D. P.; Di Carlo, A.; Dini, D. Comparison of the photoelectrochemical properties of $\mathrm{RDS} \mathrm{NiO}$ thin films for p-type DSCs with different organic and organometallic dye-sensitizers and evidence of a direct correlation between cell efficiency and charge recombination. J. Solid State Electrochem. 2015, 19, 975-986.

(71) Fabregat-Santiago, F.; Bisquert, J.; Palomares, E.; Otero, L.; Kuang, D.; Zakeeruddin, S. M.; Gratzel, M. Correlation between photovoltaic performance and impedance spectroscopy of dyesensitized solar cells based on ionic liquids. J. Phys. Chem. C 2007, $111,6550-6560$.

(72) Novelli, V.; Awais, M.; Dowling, D. P.; Dini, D. Electrochemical characterization of rapid discharge sintering (RDS) $\mathrm{NiO}$ cathodes for dye-sensitized solar cells of $p$-Type. Am. J. Anal. Chem. 2015, 6, 176187.

(73) Awais, M.; Dini, D.; Don MacElroy, J. M.; Halpin, Y.; Vos, J. G.; Dowling, D. P. Electrochemical characterization of $\mathrm{NiO}$ electrodes deposited via a scalable powder microblasting technique. J. Electroanal. Chem. 2013, 689, 185-192.

(74) Park, J.; Barbero, N.; Yoon, J.; Dell'Orto, E.; Galliano, S.; Borrelli, R.; Yum, J. H.; Di Censo, D.; Grätzel, M.; Nazeeruddin, M. $\mathrm{K}$; et al. Panchromatic symmetrical squaraines: a step forward in the molecular engineering of low cost blue-greenish sensitizers for dyesensitized solar cells. Phys. Chem. Chem. Phys. 2014, 16, 24173-24177.

(75) Ho, Y. S.; McKay, G. A comparison of chemisorption kinetic models applied to pollutant removal on various sorbents. Process Saf. Environ. Prot. 1998, 76, 332-340.

(76) Biswas, I.; Peisert, H.; Schwieger, T.; Dini, D.; Hanack, M.; Knupfer, M.; Schmidt, T.; Chassé, T. Tetra-t-butyl magnesium phthtalocyanine on gold: Electronic structure and molecular orientation. J. Chem. Phys. 2005, 122, 064710.

(77) Dick, S.; Peisert, H.; Dini, D.; Hanack, M.; Cook, M. J.; Chambrier, I.; Chassé, T. Influence of the alkyl-chains length on the electronic structure and interface properties of 1,4-octasubstituted zinc phthalocyanines thin films on gold. J. Appl. Phys. 2005, 97, 073715.

(78) Haug, A.; Harbeck, S.; Dini, D.; Hanack, M.; Cook, M. J.; Peisert, H.; Chassé, T. Alkyl chain effects in thin films of substituted phthalocyanines studied using infrared spectroscopy. Appl. Surf. Sci. 2005, 252, 139-142. 
(79) Peisert, H.; Biswas, I.; Zhang, L.; Knupfer, M.; Hanack, M.; Dini, D.; Batchelor, D.; Chassé, T. Molecular orientation of substituted phthalocyanines: influence of the substrate roughness. Surf. Sci. 2006, 600, 4024-4029.

(80) Biswas, I.; Peisert, H.; Zhang, L.; Chassé, T.; Knupfer, M.; Hanack, M.; Dini, D.; Schmidt, T.; Batchelor, D. Orientation of differently substituted phthalocyanines: first layers and thin films. Mol. Cryst. Liq. Cryst. 2006, 455, 241-249.

(81) Kabatc, J.; Kostrzewska, K.; Jurek, K.; Dobosz, R.; Orzel, L. 1,3Bis(phenylamino)squaraine- photophysical and photochemical properties. Dyes Pigm. 2016, 127, 179-186.

(82) Warnan, J.; Gardner, J.; Le Pleux, L.; Petersson, J.; Pellegrin, Y.; Blart, E.; Hammarström, L.; Odobel, F. Multichromophoric sensitizers based on squaraine for $\mathrm{NiO}$ based dye-sensitized solar cells. J. Phys. Chem. C 2014, 118, 103-113.

(83) Zhu, H.; Hagfeldt, A.; Boschloo, G. Photoelectrochemistry of mesoporous $\mathrm{NiO}$ electrodes in iodide/triiodide electrolytes. J. Phys. Chem. C 2007, 111, 17455-17458.

(84) Gibson, E. A.; Le Pleux, L.; Fortage, J.; Pellegrin, Y.; Blart, E.; Odobel, F.; Hagfeldt, A.; Boschloo, G. Role of the triiodide/iodide redox couple in dye regeneration in p-type dye-sensitized solar cells. Langmuir 2012, 28, 6485-6493.

(85) Ameline, D.; Diring, S.; Farre, Y.; Pellegrin, Y.; Naponiello, G.; Blart, E.; Charrier, B.; Dini, D.; Jacquemin, D.; Odobel, F. Isoindigo derivatives for application in p-type dye sensitized solar cells. RSC Adv. 2015, 5, 85530-85539.

(86) Bisquert, J. Theory of the impedance of electron diffusion and recombination in a thin layer. J. Phys. Chem. B 2002, 106, 325-333.

(87) Bisquert, J. Chemical capacitance of nanostructured semiconductors: its origin and significance for nanocomposite solar cells. Phys. Chem. Chem. Phys. 2003, 5, 5360-5364.

(88) Gregg, B. A. Interfacial processes in the dye-sensitized solar cell. Coord. Chem. Rev. 2004, 248, 1215-1224.

(89) Hagfeldt, A.; Cappel, U. B.; Boschloo, G.; Sun, L.; Kloo, L.; Pettersson, H.; Gibson, E. A. Dye sensitized photoelectrochemical cells. In Practical Handbook of Photovoltaics: Fundamentals and Applications, 2nd Ed.; McEvoy, A., Markvart, T., Castaner, L., Eds.; Elsevier: Amsterdam, 2012; pp 479-542. 